Article

\title{
The Analysis of the Aftershock Sequences of the Recent Mainshocks in Alaska
}

\author{
Mohammadamin Sedghizadeh *(D) and Robert Shcherbakov
}

check for updates

Citation: Sedghizadeh, M.;

Shcherbakov, R. The Analysis of the Aftershock Sequences of the Recent Mainshocks in Alaska. Appl. Sci. 2022, 12, 1809. https://doi.org/ 10.3390/app12041809

Academic Editor: Amadeo Benavent-Climent

Received: 19 December 2021

Accepted: 5 February 2022

Published: 10 February 2022

Publisher's Note: MDPI stays neutral with regard to jurisdictional claims in published maps and institutional affiliations.

Copyright: (C) 2022 by the authors. Licensee MDPI, Basel, Switzerland. This article is an open access article distributed under the terms and conditions of the Creative Commons Attribution (CC BY) license (https:// creativecommons.org/licenses/by/ $4.0 /)$.
Department of Earth Sciences, University of Western Ontario, London, ON N6A 5B7, Canada; rshcherb@uwo.ca * Correspondence: msedghiz@uwo.ca

\begin{abstract}
The forecasting of the evolution of natural hazards is an important and critical problem in natural sciences and engineering. Earthquake forecasting is one such example and is a difficult task due to the complexity of the occurrence of earthquakes. Since earthquake forecasting is typically based on the seismic history of a given region, the analysis of the past seismicity plays a critical role in modern statistical seismology. In this respect, the recent three significant mainshocks that occurred in Alaska (the 2002, Mw 7.9 Denali; the 2018, Mw 7.9 Kodiak; and the 2018, Mw 7.1 Anchorage earthquakes) presented an opportunity to analyze these sequences in detail. This included the modelling of the frequency-magnitude statistics of the corresponding aftershock sequences. In addition, the aftershock occurrence rates were modelled using the Omori-Utsu (OU) law and the Epidemic Type Aftershock Sequence (ETAS) model. For each sequence, the calculation of the probability to have the largest expected aftershock during a given forecasting time interval was performed using both the extreme value theory and the Bayesian predictive framework. For the Bayesian approach, the Markov Chain Monte Carlo (MCMC) sampling of the posterior distribution was performed to generate the chains of the model parameters. These MCMC chains were used to simulate the models forward in time to compute the predictive distributions. The calculation of the probabilities to have the largest expected aftershock to be above a certain magnitude after a mainshock using the Bayesian predictive framework fully takes into account the uncertainties of the model parameters. Moreover, in order to investigate the credibility of the obtained forecasts, several statistical tests were conducted to compare the performance of the earthquake rate models based on the OU formula and the ETAS model. The results indicate that the Bayesian approach combined with the ETAS model produced more robust results than the standard approach based on the extreme value distribution and the OU law.
\end{abstract}

Keywords: epidemic type aftershock sequence model; extreme value distribution; Bayesian predictive distribution

\section{Introduction}

The Pacific Ring of Fire is one of the most seismically active regions of the world. Alaska and western Canada are a part of this ring and are prone to the occurrence of significant earthquakes. This geographic region is characterized by high seismic activity and is capable of producing megathrust earthquakes. These earthquakes can pose significant hazard and are also capable of triggering tsunamis or intense ground shaking [1] and subsidiary hazards such as liquefaction, landslides and aftershocks [2]. While tsunamis pose a serious threat to coastal areas, ground shaking can cause damage to infrastructure and endanger human life. Therefore, it is important to perform a comprehensive statistical analysis of the aftershock sequences in the Aleutian subduction zone and central Alaska. Moreover, the occurrence of large aftershocks poses a significant risk to the infrastructure that has been affected by a mainshock. Therefore, estimating the probabilities for the occurrence of the largest expected aftershocks plays an important role in post-mainshock decision-making $[3,4]$. 
One of the earliest empirical studies of the difference between the magnitude of the mainshock and its largest aftershock was conducted by Båth [5], who postulated that the largest aftershock is on average 1.2 magnitudes lower than the mainshock regardless of the magnitude of the mainshock. Vere-Jones [6,7] proposed that the magnitude difference between the mainshock and the largest aftershock was independent of the number of events. Reasenberg and Jones [8] were one of the first in developing an aftershock forecasting model. They introduced a parametric model that was capable of computing the probabilities of aftershocks in a certain time window after a mainshock for California. Michael et al. [9] proposed the methodology which aforementioned model parameters can be estimated with Bayesian updating from both the ongoing aftershock sequence and from historic aftershock sequences.

An important step in the calculation of the probability of having an earthquake above a certain magnitude is the estimation of the model parameters that describe the seismicity rate and the frequency-magnitude distribution. Those parameters are highly dependent on the lower cut-off magnitude, $m_{0}$. The correct estimation of the cut-off magnitude plays a crucial role in earthquake forecasting and modelling. Mignan and Woessner [10] emphasized that a high-value of the cut-off magnitude can result in under-sampling of useful data and a low-value of the cut-off magnitude can result in uncertainty and bias of the estimated seismicity parameters and forecasting model, respectively.

The other issue in aftershock forecast modelling is the catalogue incompleteness right after the occurrence of strong mainshocks [11,12]. This early catalogue incompleteness can affect significantly the estimation of the parameters of the earthquake decay rate. The uncertainties in the estimation of the parameters of the aftershock decay rate can result in significant miscalculation of the probabilities for the occurrence of largest events. The empirical prior probability distribution was presented by Omi et al. [13] to reduce the uncertainty of the parameter estimation of the ETAS model regarding the incompleteness of the earthquake catalogues.

Utilizing generic parameters to create an aftershock forecast model for the early days after the mainshocks is one of the possible ways to control the catalogue incompleteness. Page et al. [14] introduced a method for generic parameter estimation by using tectonic zoning of García et al. [15] to improve the spatial distribution of forecasted events. In this approach, Bayes' rule and aftershock records are used to update the generic parameters. In addition, the distribution of the regional generic parameters can be considered as a prior and the aftershock data can be used to calculate the posterior distribution. Michael et al. [9] applied this approach to the 2018 Anchorage aftershock sequence. They reported that the use of the generic parameters for the forecast model leads to the overestimation of the seismic activity.

One of the critical tasks in statistical seismology is the ability to accurately and reliably forecast the evolution of earthquake sequences. A consistent approach for earthquake forecast testing has been implemented in the Collaboratory for the Study of Earthquake Predictability (CSEP) [16-19]. In this framework, the gridded rate forecast is used in which the selected geographic area is separated into zones then the number of earthquakes in each zone is estimated [19]. In addition, the number of earthquakes in each forecast bin is considered to be independent of the other bins and follows the Poisson distribution. Several statistical tests were developed as part of the CSEP framework to examine earthquake forecasts. As a result of these developments, it is possible to determine if a particular forecasting scheme is able to accurately replicate locations, magnitudes, and the observed numbers of earthquakes $[19,20]$. Various forecasting algorithms can also be compared using the aforementioned likelihood-based tests. For example, retrospective aftershock forecasting of the 2011 Tohoku, Japan; 2010 Canterbury, New Zealand; 2016 Kaikoura, New Zealand; and 2019 Ridgecrest, California earthquakes were tested by using this approach [4,21-24].

In this study, the analysis of three major earthquake sequences that occurred in Alaska in the past 20 years was conducted to test retrospectively the ability to forecast the magni- 
tudes of the largest expected aftershocks. Specifically, the 23 January 2018 Mw 7.9 Kodiak earthquake occurred in the Gulf of Alaska near Kodiak Island at 09:31:40.89 UTC at a depth of $14 \mathrm{~km}[25,26]$. There was no significant damage reported. The earthquake woke residents in Anchorage which was located $560 \mathrm{~km}$ northeast from the epicenter. It was also felt in parts of British Columbia, Canada. The $2018 \mathrm{Mw} 7.1$ Anchorage earthquake happened approximately $15 \mathrm{~km}$ north from Anchorage, Alaska on 30 November of 2018 at 17:29:29.33 UTC at a depth of $46.7 \mathrm{~km}[9,27]$. A few minutes later, a magnitude 5.8 aftershock shook the region. Significant damage has been reported to infrastructure, buildings, and airports [9]. Moreover, we investigated the characteristics of the 3 November 2002, Mw 7.9 Denali earthquake that occurred in central Alaska along a shallow strike-slip fault on the Denali-Totschunda fault system $[28,29]$. The details of the selected mainshocks are listed in Table 1 and the spatial distributions of the mainshocks with the corresponding aftershock sequences during the first 14 days are shown in Figure 1.

Table 1. The dates of occurrence, epicentre locations, magnitude and depth of the analyzed mainshocks.

\begin{tabular}{ccccccc}
\hline Name & Date & Time & Latitude & Longitude & Magnitude & Depth \\
\hline Denali & 3 November 2002 & $22: 12: 41$ & 63.5141 & -147.4529 & $7.9 \mathrm{Mw}$ & $4.2 \mathrm{~km}$ \\
Kodiak & 23 January 2018 & $09: 31: 40$ & 56.0039 & -149.1658 & $7.9 \mathrm{Mw}$ & $14 \mathrm{~km}$ \\
Anchorage & 30 November 2018 & $17: 29: 29$ & 61.3464 & -149.9552 & $7.1 \mathrm{Mw}$ & $46.7 \mathrm{~km}$ \\
\hline
\end{tabular}

In this study, the left truncated exponential distribution was utilized to model the magnitude frequency statistics [30]. Moreover, the modified Omori-Utsu (OU) law [31] and Epidemic Type Aftershock Sequence (ETAS) model [32] were used to approximate the rate of the aftershocks. In addition, two statistical approaches including the extreme value distribution and Bayesian predictive distribution were utilized to compute the probabilities of having the largest expected aftershocks to be above a certain magnitude during the evolution of each sequence.

The paper is structured as follows: Section 2 begins with the specification of the earthquake catalogues and follows by defining the statistical methods to analyze the aftershock sequences. The results of the statistical analysis are provided in Section 3. In Section 4, discussion of the results and concluding remarks are given.

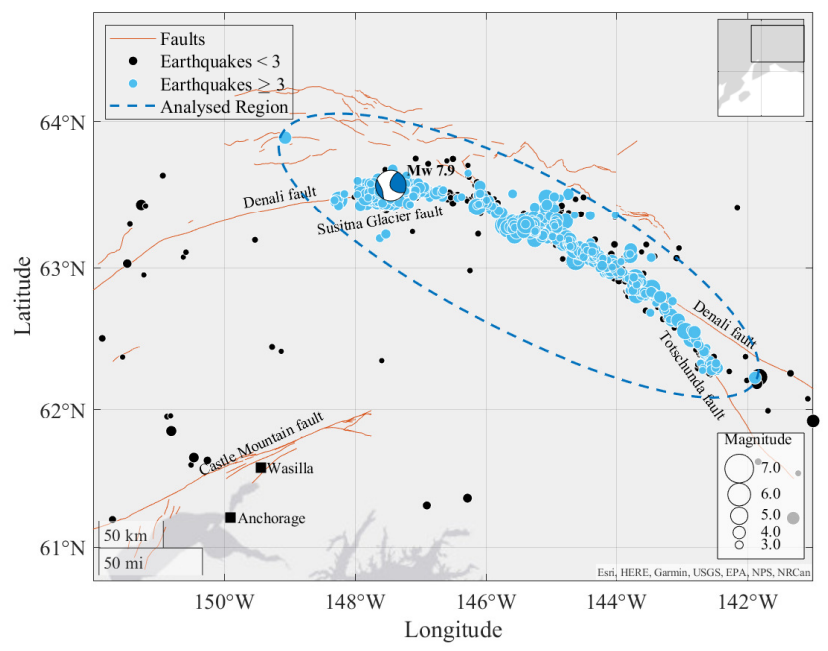

(a)

Figure 1. Cont. 


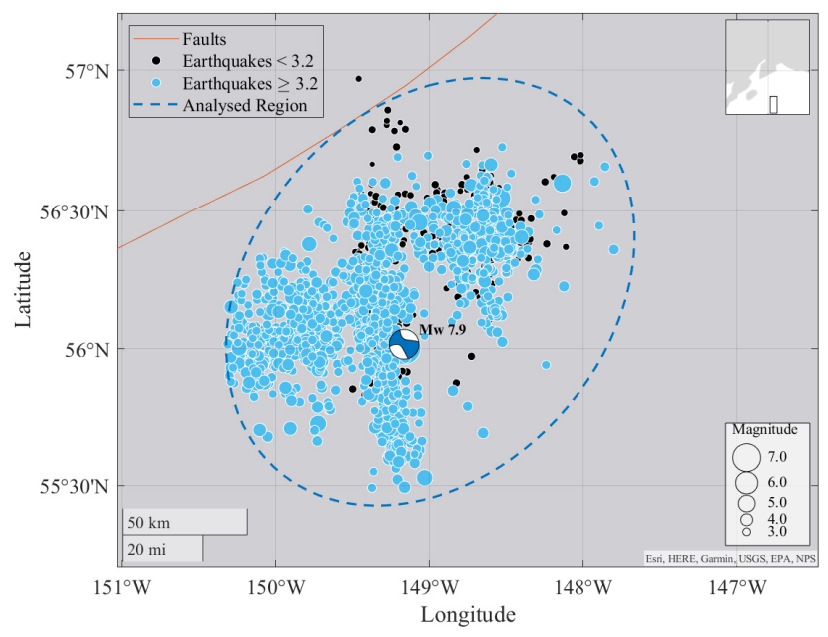

(b)



(c)

Figure 1. Maps of the occurrence of the aftershock sequences generated by the three significant Alaska mainshocks: (a) the $2002 \mathrm{Mw} 7.9$ Denali sequence with $m_{0}=3.0$; (b) the 2018, Mw 7.9 Kodiak sequence with $m_{0}=3.2$; and (c) the $2018 \mathrm{Mw} 7.1$ Anchorage sequence with $m_{0}=2.8$. The events during 30 days after each mainshock are plotted. The blue solid circles represent the aftershocks above $m_{0}$. Black points are all events between magnitude 2.5 and $m_{0}$. The focal mechanisms of the studied mainshocks are plotted as beach balls. Quaternary faults are plotted as light brown line segments [33].

\section{Materials and Methods}

\subsection{Earthquake Catalogue}

In order to analyze the 2002, Mw 7.9 Denali; the 2018, Mw 7.9 Kodiak, and the 2018, Mw 7.1 Anchorage earthquake sequences, the United States Geological Survey (USGS) earthquake catalogue https:/ / earthquake.usgs.gov / earthquakes/search/ (accessed on 18 December 2021) was used. The spatial distribution of aftershocks during 30 days after each mainshock are shown in Figure 1. The focal mechanisms of the mainshocks were obtained from the USGS website [34-36].

The 2002 Denali, Alaska, earthquake sequence occurred along the Denali-Totschunda faults which is a right-lateral strike-slip fault system. The Mw 7.9 mainshock nucleated on the Susitna Glacier thrust fault and propagated further along the Denali fault and continued along the Totschunda fault [29]. The parameters of the elliptical region for this aftershock sequence, are given in Table 2 and the sequence for 30-day is depicted in Figure 1a. The plotted fault plane solution for this mainshock in Figure 1a was taken from the the USGS website [34]. 
The 2018 Mw 7.9 Kodiak, Alaska, earthquake took place in the Gulf of Alaska southeast of Kodiak Island. The mainshock location and the focal mechanism reflect a strike-slip faulting system within the shallow lithosphere of the Pacific plate near the subduction zone [37]. In Table 2 the details of the studied sequence for this mainshock are reported. In addition, the earthquake sequence during 30-day after the mainshock occurrence is demonstrated in Figure 1b. The focal mechanism of the 2018 Mw 7.9 Kodiak, Alaska, earthquake suggests a steeply dipping fault either as a right-lateral system that strikes the north-northwest or as a left-lateral fault that strikes west-southwest. The fault plane solution for the mainshock in Figure $1 \mathrm{~b}$ was obtained from the USGS website [35].

The $2018 \mathrm{Mw} 7.1$ Anchorage, Alaska, earthquake happened as the result of a normal faulting rupturing north from Anchorage, Alaska. The location and mechanism of the focal mechanism reflect a moderately dipping north-south fault system fault within the subducting Pacific slab [38,39]. Details of the analyzed earthquake sequence are presented in Table 2 and the sequence of 30-day is illustrated in Figure 1c. The indicated moment tensor for this mainshock in Figure 1c was acquired from USGS [36].

Table 2. The parameters of the elliptical regions used for the identification of the aftershock sequence and the corresponding lower magnitude cutoffs $m_{0}$.

\begin{tabular}{|c|c|c|c|c|c|c|c|}
\hline \multirow{3}{*}{ Mainshock Name } & \multirow{3}{*}{ Start Date and Time } & \multicolumn{5}{|c|}{ Elliptical Aftershock Zone } & \multirow{3}{*}{ Magnitude Cut-Off, $m_{0}$} \\
\hline & & \multicolumn{2}{|c|}{ Center } & \multirow{2}{*}{ Declination } & \multicolumn{2}{|c|}{ Radii } & \\
\hline & & Latitude & Longitude & & $R_{1}$ & $R_{2}$ & \\
\hline Denali & 3 November 2002 (22:12:41) & 63.1 & -145.40 & 117.5 & 1.85 & 0.55 & 3.0 \\
\hline Kodiak & 23 January 2018 (09:31:40) & 56.2 & -149 & 40 & 0.85 & 0.65 & 3.2 \\
\hline Anchorage & 30 November 2018 (17:29:29) & 61.425 & -149.91 & 35 & 0.22 & 0.16 & 2.8 \\
\hline
\end{tabular}

For the statistical analysis of seismicity, several time intervals were utilized to estimate properly the parameters of the models describing the evolution and the statistics of the aftershock sequences. For the estimation of the model parameters, the training time interval, $\left[T_{0}, T_{e}\right]$, is considered. In order to properly account for the impact of preceding earthquakes on the earthquake rate, the training time interval is divided into an initial time interval, $\left[T_{0}, T_{s}\right]$, and a target time interval, $\left[T_{s}, T_{e}\right]$. The seismicity parameters are estimated in the target time interval. A forecasting time interval, $\left[T_{e}, T_{e}+\Delta T\right]$ is also considered to analyze the evolution and the statistics of the seismicity. The schematic illustration of the time intervals for the analysis of the aftershock sequences is shown in Figure 2.

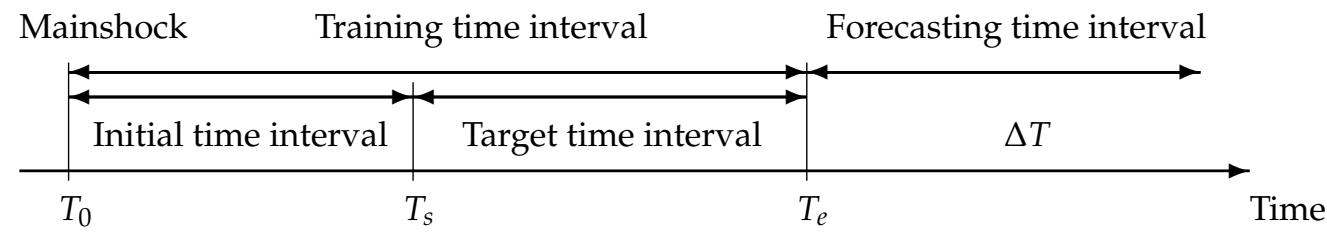

Figure 2. An illustration of the time intervals used in the analysis.

Earthquakes occur due to sudden energy release associated with the slippage of faults and are characterized by finite rupture areas. However, for statistical analysis of seismicity, the point assumption is utilized to characterize each earthquake. On time scales larger than the propagation of rupture along the fault, earthquakes can be treated as points in time and space. This idealization helps to describe the earthquake process by point process models. The point process becomes a marked point process by assigning magnitudes to each event. Therefore, each earthquake can be characterized by the magnitude, $m_{i}$, and the occurrence time, $t_{i}$, in order to generate a stochastic marked point process during a specific time interval, $S=\left\{\left(t_{i}, m_{i}\right)\right\}: i=1,2, \ldots, n$. 


\subsection{Gutenberg-Richter Scaling and the Exponential Distribution}

Gutenberg and Richter [40] proposed the relationship that describes the frequencymagnitude statistics of earthquakes. This relationship between the frequency of event occurrences and the event magnitudes is one of the most commonly used empirical laws in statistical seismology. They suggested the following equation:

$$
N(m \geq)=10^{(a-b m)},
$$

where $N(m \geq)$ is the total number of earthquakes above magnitude $m$ and $N(0 \geq)=10^{a}$ and $b$ is the value of the slope of the fitted line to the $N$ on a logarithmic scale. VereJones [30] emphasized that the distribution of earthquake magnitudes is described by the exponential distribution for $m \geq m_{0}$ with the probability density, $f_{\theta}(m)$, and cumulative distribution function, $F_{\theta}(m)$ :

$$
\begin{gathered}
f_{\theta}(m)=\beta e^{-\beta\left(m-m_{0}\right)}, \\
F_{\theta}(m)=1-e^{-\beta\left(m-m_{0}\right)},
\end{gathered}
$$

where $m_{0}$, is the lower magnitude cut-off that is above the catalogue completeness magnitude $m_{c}$ and $\theta=\{\beta\}$ is the model parameter which can be obtained from all earthquakes above $m_{0}$ in target time interval $\left[T_{s}, T_{e}\right]$. The parameter $\beta$ is related to the $b$-value of the Gutenberg-Richter (GR) scaling:

$$
\beta=b \ln (10) .
$$

The Maximum Likelihood Estimation (MLE) is the most common approach to estimate the $b$-value or parameter $\beta$. Bender [41] suggested an estimator for $\beta$ by taking into account the binning of the magnitude. Tinti and Mulargia [42] proposed an approach to calculate the uncertainties of the parameter $\beta$ at a given confidence level.

\subsection{Omori-Utsu Law}

For the first time, Omori [43] introduced a formula for the aftershock sequence decay rate, $\lambda(t)$, that is inversely related to the elapsed time after the mainshock. Utsu [31] proposed a modification of the Omori law which is known as the Omori-Utsu (OU) law. Utsu [31] modified the original intensity to the following form:

$$
\lambda_{\omega}(t)=\frac{K}{(t+c)^{p}},
$$

where $\lambda_{\omega}(t)$ is the earthquake rate at a given time $t$ with magnitudes above $m_{0}$, and set of parameters $\omega=\{K, c, p\}$, and $t$ is the time elapsed since the occurrence of the mainshock at $T_{0}=0$. The parameter $K$ is the productivity of the sequence, $c$ is the characteristic time, and $p$ is the rate of the decay in time. By considering the non-homogeneous Poisson process for the occurrence of earthquakes, the parameters $\omega=\{K, c, p\}$ can be determined by using the MLE approach $[44,45]$. In addition, in this model, the parameter uncertainties can be estimated from the inverse of the Fisher information matrix that is computed from the likelihood function.

\subsection{The Epidemic Type Aftershock Sequence (ETAS) Model}

A more realistic approximation of the earthquake rate was proposed by Ogata [46], where he suggested that each earthquake could be considered as a trigger for the next events in the sequence. The conditional intensity of the temporal ETAS model, $\lambda_{\omega}\left(t \mid \mathcal{H}_{t}\right)$, at time $t$ is defined as [46]:

$$
\lambda_{\omega}\left(t \mid \mathcal{H}_{t}\right)=\mu+A \sum_{i: t_{i}<t}^{N_{t}} \frac{e^{\alpha\left(m_{i}-m_{0}\right)}}{\left(\frac{t-t_{i}}{c}+1\right)^{p}}
$$


where $\omega=\{\mu, A, c, p, \alpha\}$ is the set of parameters of temporal conditional intensity with a reference magnitude $m_{0}$ and the occurrence history of earthquakes, $\mathcal{H}_{t}$, during the time interval $\left[T_{0}, t\right] . N_{t}$ is the number of the earthquakes with magnitudes above $m_{0}$ in the time interval $\left[T_{0}, t\right]$. In the ETAS model, $\mu$ specifies the average rate of background events that transpire independently of any other events. $c$ is the temporal characteristic time, $p$ governs the rate of decay of triggered events as a power law, and $A$ controls the event productivity. The parameter $\alpha$ determines the degree of aftershock clustering. Larger values of $\alpha$ correspond to more pronounced aftershock sequences with stronger variability in earthquake magnitudes. In contrast, the impact of event's magnitude on aftershock generation is reduced by smaller $\alpha$ values. The estimation of the ETAS model parameters is achieved by maximizing the log-likelihood function:

$$
\log L=\sum_{i: t_{i} \leq T_{e}} \lambda_{\omega}\left(t_{i} \mid \mathcal{H}_{t_{i}}\right)-\int_{T_{s}}^{T_{e}} \lambda_{\omega}\left(t \mid \mathcal{H}_{t}\right) d t
$$

In general, the consistency of the ETAS model is measured on the basis of a transformed time. The transformed time $\tau_{i}$ for a given event is computed by using the cumulative conditional intensity at time $t_{i}$ as

$$
\tau_{i}=\int_{0}^{t_{i}} \lambda_{\omega}(t) d t
$$

If the fit of the model is accurate, the sequence of earthquakes should obey a stationary Poisson process in the transformed time. Furthermore, the cumulative number of observed earthquakes in transformed time can be close to a straight line [13]. The deviation of the cumulative number of observed events from the straight line indicates that the model does not fit well the earthquake sequence.

\subsection{Extreme Value Distribution}

By considering a non-homogeneous Poisson sequence of earthquakes, the probability of having an extreme earthquake with a magnitude above $m$ in the forecasting time interval, $\left[T_{e}, T_{e}+\Delta T\right]$ can be obtained from the Extreme Value Distribution (EVD) [47]:

$$
\operatorname{Pr}_{E V}\left\{m_{e x} \geq m \mid \theta, \omega, \Delta T\right\}=1-e^{-\left\{\Lambda_{\omega}(\Delta T)\left[1-F_{\theta}(m)\right]\right\}},
$$

where $m_{e x}$ is the magnitude of the largest expected event, $\omega$ is the set of parameters of seismicity rate $\lambda_{\omega}(t), F_{\theta}(m)$ is the cumulative distribution function of the events' magnitude with the set of parameters $\theta$, and $\Lambda_{\omega}(\Delta t)$ is a productivity function that is given as:

$$
\Lambda_{\omega}(\Delta T)=\int_{T_{e}}^{T_{e}+\Delta T} \lambda_{\omega}(t) d t
$$

By considering the exponential model, Equation (3), for describing the magnitude distribution and the UO model, Equation (5), for the intensity of the productivity function, Equation (9) can be rewritten as:

$$
\begin{aligned}
& \operatorname{Pr}_{E V}\left\{m_{e x} \geq m \mid \theta, \omega, \Delta T\right\}= \\
& 1-\exp \left\{-\left[K \frac{\left(T_{e}+c\right)^{1-p}-\left(T_{e}+\Delta T+c\right)^{1-p}}{p-1}\right]\left(e^{-\beta\left(m-m_{0}\right)}\right)\right\},
\end{aligned}
$$

for $p \neq 1$, and the set of parameters $\{\theta, \omega\}$ can be obtained during the target time interval $\left[T_{s}, T_{e}\right]$. Therefore from Equation (11), the probability of having an earthquake with a magnitude above $m$ in a forecast time interval $\left[T_{e}, T_{e}+\Delta T\right]$ can be obtained, which is the same approach as in Reasenberg and Jones [8]. 


\subsection{Bayesian Predictive Distribution}

The obtained parameters of the aftershock sequence model during the training time interval play a crucial role in calculating the EVD. The uncertainty of the parameters have a significant impact on the calculation of the corresponding probabilities. Shcherbakov et al. $[3,48]$ incorporated the model uncertainties into the computation of the probabilities for the occurrence of the largest expected earthquakes by applying the Bayesian predictive distribution (BPD) approach, in which the BPD can be defined as:

$$
\operatorname{Pr}_{B}\left\{m_{e x} \geq m \mid S, \Delta t\right\}=\int_{\Omega} \int_{\Theta} \operatorname{Pr}_{E V}\left(m_{e x} \geq m \mid \theta, \omega, \Delta T\right) p(\theta, \omega \mid S) d \theta d \omega,
$$

where $\Theta$ and $\Omega$ are the frequency-magnitude distribution and seismicity rate parameter domains, respectively. $\operatorname{Pr}_{E V}\left(m_{e x} \geq m \mid \theta, \omega, \Delta T\right)$ is the EVD and $p(\theta, \omega \mid S)$ is the posterior distribution function, which quantifies the uncertainties of the model parameters.

Since the ETAS model deviates from a non-homogeneous Poisson process the EVD for the largest magnitudes is not given by Equation (9). Shcherbakov et al. [3] suggested to use the stochastic simulations to approximate the extreme value distribution and ultimately the BPD. In this approach, the Metropolis-within-Gibbs algorithm is used to sample from the conditional posterior distribution to generate the chain of the model parameters using the Markov Chain Monte Carlo (MCMC), then the model parameter chain is used to simulate the ETAS model during the forecasting time interval $\left[T_{e}, T_{e}+\Delta T\right]$. At the end, the maximum magnitude is taken from each sequence of events to construct a distribution that approximates the BPD.

When performing MCMC sampling a certain initial part of the parameter chain is discarded as "burn-in". The Gamma distribution was considered for the prior distribution of the model parameters. As burn-in the first 50\% of Markov chains were discarded and the second half was utilized for calculation of the BPD.

\subsection{Forecast Validation}

To evaluate the number of forecasted earthquakes by a specific model in the forecasting time interval, the $\mathrm{N}$-test can be used $[4,17,19,49]$. It tests the distribution range of the number of the forecasted events versus the number of observed earthquakes. In addition, in order to test the magnitude distribution of the forecasted earthquakes the M-test can be applied $[4,17,19,49]$. The $\mathrm{N}$ and M-tests examine the consistency of the forecasts with respect to observations, and the R-test can be used to compare the performance of different forecasting models [17]. In addition, to evaluate statistical forecast the T-test can be applied [49]. In formulating the T-test, the sample information gain per earthquake of the model $\Lambda^{2}$ over the model $\Lambda^{1}$ is defined as $I_{N}\left(\Lambda^{2}, \Lambda^{1}\right)=R^{21} / N_{\text {obs }}$, where $N_{\text {obs }}$ is the number of observed earthquakes during the forecasting time interval $\Delta T$ and $R^{21}=L\left(\mathrm{M} \mid \Lambda^{2}\right)-L\left(\mathrm{M} \mid \Lambda^{1}\right)$ is the log-likelihood ratio of the two models. The detailed explanation and implementation of these tests applied to the time-dependent models such as the ETAS and OU rates can be found in Shcherbakov [4].

\section{Results}

In this section the obtained results of the analysis of the recent three significant mainshocks that occurred in Alaska (the 2002, Mw 7.9 Denali; the 2018, Mw 7.9 Kodiak, and the 2018; Mw 7.1 Anchorage earthquakes) are summarized.

\subsection{Frequency-Magnitude Statistics Analysis}

The aftershocks of the three mainshocks within elliptical regions as shown in Figure 1 were used to obtain the frequency-magnitude statistics. The fitting of Equation (2) was done to all three sequences and during specific target time intervals. To estimate the parameter $\beta$ from Equation (2) the MLE approach was used [41]. The model parameter uncertainties were estimated using the method of Tinti and Mulargia [42]. In addition, the method of goodness of fit test [50] was utilized to estimate the magnitude of completeness $m_{c}$ for the 
three sequences. Specifically, $m_{0}$ was selected as the magnitude above which at least $95 \%$ of the observed data are modeled by Equation (2). The results are presented in Figure 3. Moreover, to investigate how the earthquake magnitudes evolve over time, they are plotted versus the sequential number in Figure A1. This can be used to inspect the early magnitude incompleteness of aftershock sequences and can be used to justify the use of a chosen magnitude threshold [51].

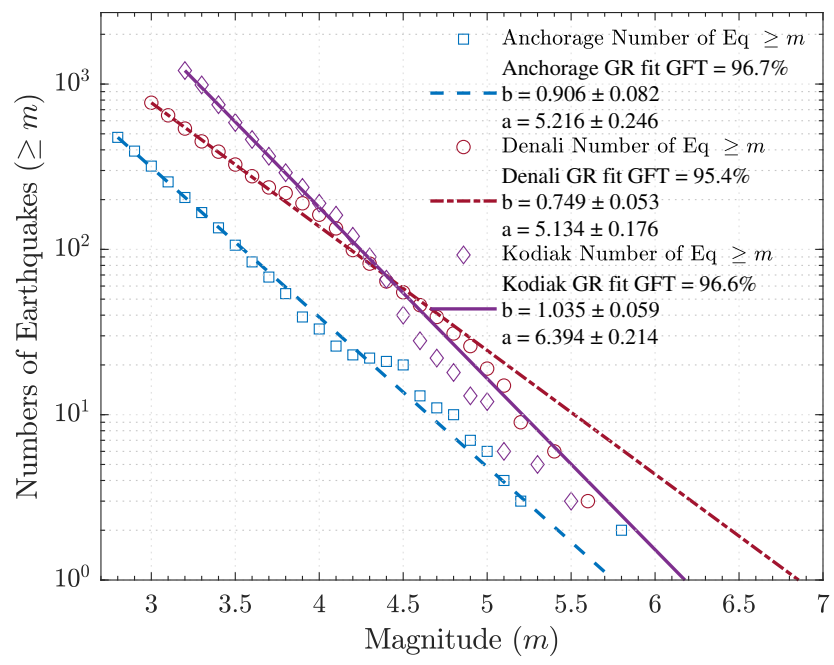

Figure 3. The frequency-magnitude statistics of aftershock sequences for 30 days from the mainshock occurrence. The lines are the Gutenberg-Richter scaling fit, Equation (1). The open symbols represent the cumulative numbers corresponding to each aftershock sequence. The estimated $a$ and $b$-value with $95 \%$ confidence intervals are given in the legend. The cumulative numbers of aftershocks for the 2002, Denali aftershocks for $m \geq 3.0$ are plotted as red circles, the 2018, Kodiak aftershocks for $m \geq 3.2$ cumulative numbers are plotted as purple diamonds, and blue squares are used to depict the 2018, Anchorage aftershocks for $m \geq 2.8$.

In order to analyze the frequency-magnitude statistics of the 2002, Denali earthquake sequence, $m_{0}=3.0$ was considered as a cut-off magnitude, and the analysis was performed during $\left[T_{s}, T_{e}\right]=[0,30]$ days after the mainshock occurrence on 3 November 2002 (22:12:41 UTC) for the earthquakes within the elliptical region given in Figure 1a. The total number of aftershocks during the selected time interval was 771 with the maximum magnitude 5.6, respectively. The fit of the GR relation is demonstrated in Figure 3. The estimated $b$-value and $a$-value for the analyzed earthquake sequence are $0.749 \pm 0.053$ and $5.134 \pm 0.176$, respectively. The magnitude-frequency statistics analysis of the 2018, Kodiak earthquake sequence was performed during $\left[T_{s}, T_{e}\right]=[0,30]$ days after the mainshock that occurred on 23 January 2018 (09:31:4 UTC) for earthquakes with the cut-off magnitude $m_{0}=3.2$ within an elliptical region shown in Figure 1b. In total 1207 earthquakes with the magnitude ranging from 3.2 to 5.5 occurred in the analyzed elliptical region during the specified time interval. The estimated $b$-value and $a$-value for selected earthquake sequence are $1.035 \pm 0.059$ and $6.394 \pm 0.214$, respectively (Figure 3). For analyzing the frequencymagnitude statistics of the 2018, Anchorage earthquake sequence, $m_{0}=2.8$ was considered as a cut-off magnitude, and the analysis was carried out during $\left[T_{s}, T_{e}\right]=[0,30]$ days after the mainshock occurrence on 30 November 2018 (17:29:29 UTC) for the earthquakes within an elliptical region of Figure 1c. In total 476 earthquakes within the magnitude range of 2.8-5.2 occurred in the analyzed spatiotemporal window. The obtained $b$-value and $a$-value for Anchorage earthquake sequence are $0.906 \pm 0.082$ and $5.216 \pm 0.246$ respectively. The fit of the GR relation is plotted in Figure 3. 


\subsection{Aftershock Decay Rate Modelling}

To begin with, we obtained the first-order approximation to the background seismicity rate within the presented elliptical regions in Figure 1 for each analyzed aftershock sequence. In this evaluation the background rate was estimated as the ratio of the number of earthquakes to the number of days, during the time interval that started on 1 January 2000, and ended 30 days before each mainshock. The estimated background rates, the corresponding time intervals, and cut-off magnitude for each analyzed mainshock are reported in Table 3.

Table 3. Background Seismicity Rate.

\begin{tabular}{ccccc}
\hline Name & Start Time & End Time & $m_{0}$ & $\mu$ (Events per Day) \\
\hline Denali & 1 January 2000 & 3 October 2002 & 3.0 & 0.1 \\
Kodiak & 1 January 2000 & 23 December 2017 & 3.2 & 0.005 \\
Anchorage & 1 January 2000 & 30 October 2018 & 2.8 & 0.02 \\
\hline
\end{tabular}

Subsequently, the aftershock decay rate was modeled by using the OU law, Equation (5), for the three sequences during the target time interval of $\left[T_{s}, T_{e}\right]=[0.001,30]$ days. The obtained parameters of the OU model with $95 \%$ confidence interval and the model fits are shown for the Anchorage sequence in Figure 4 and for the Denali and Kodiak sequences in Figure A2.

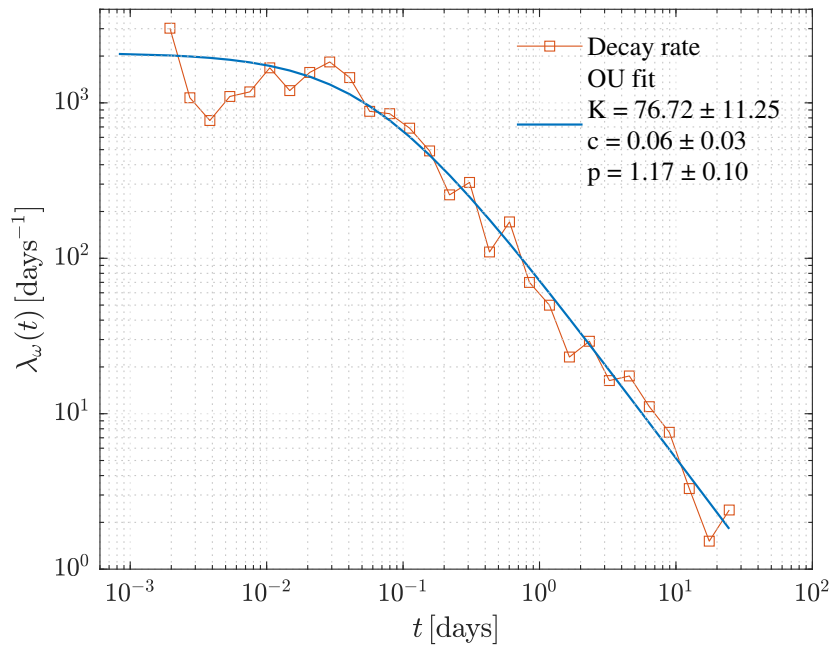

Figure 4. The log-log plot of the aftershock decay rate for the 2018, Mw 7.1 Anchorage aftershock sequence with magnitudes $m \geq 2.8$ are presented as open squares. The blue solid line is the corresponding fit of the OU law, Equation (5), to the aftershock sequence. The obtained parameters from the OU law, Equation (5), with the 95\% confidence intervals are reported in the legend.

The estimated set of parameters of the OU law, Equation (5), with 95\% confidence intervals for the 2002, Denali earthquake sequence are $\omega=\{K=202.72 \pm 48.35, c=0.29 \pm 0.13$, $p=1.22 \pm 0.11\}$ (Figure A2a). Similarly for the 2018, Kodiak earthquake sequence the obtained parameters of the OU law, Equation (5) with 95\% confidence intervals are $\omega=\{K=225.91 \pm 46.84, c=0.31 \pm 0.18, p=0.88 \pm 0.09\}$ (Figure A2b). Finally, for the 2018, Anchorage earthquake sequence the estimated parameters of the OU law are $\omega=\{K, c, p\},\{76.71 \pm 11.25,0.06 \pm 0.03,1.17 \pm 0.1\}$, respectively. The fit of the OU law and the estimated parameters from Equation (5) are demonstrated in Figure 4.

Furthermore, we used the ETAS model, Equation (6), to estimate the aftershock decay rate during the target time interval $\left[T_{s}, T_{e}\right]=[0.06,30]$ days for the three aftershock sequences. For comparison we present the OU fit and the ETAS model fit for the 2018, Anchorage earthquake sequence in Figure 5. A similar plot for the other two sequences is 
given in Figure A3. Figure 6 illustrates the fit of the ETAS model in transformed time for the 2018, Anchorage earthquake sequence.

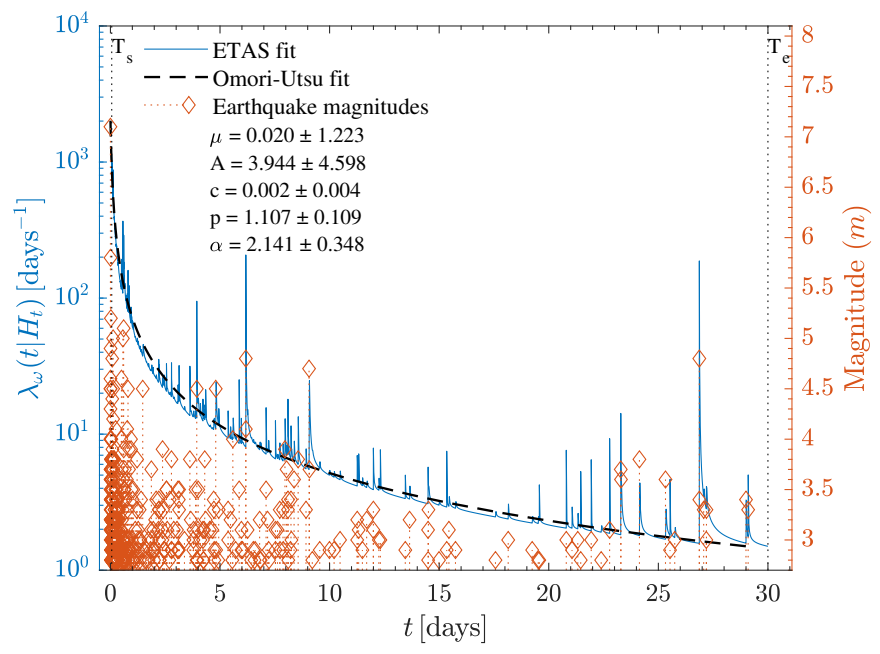

Figure 5. The aftershock sequence and corresponding earthquake magnitudes during 2018, Mw 7.1 Anchorage sequence with $m \geq 2.8$. The ETAS model fit, Equation (6), for the target time interval of $\left[T_{s}, T_{e}\right]=[0.06,30]$ is plotted as a solid blue line, and the obtained set of parameters are reported with $95 \%$ confidence intervals. The OU law fit, Equation (5), is plotted as a black dashed line for comparison.

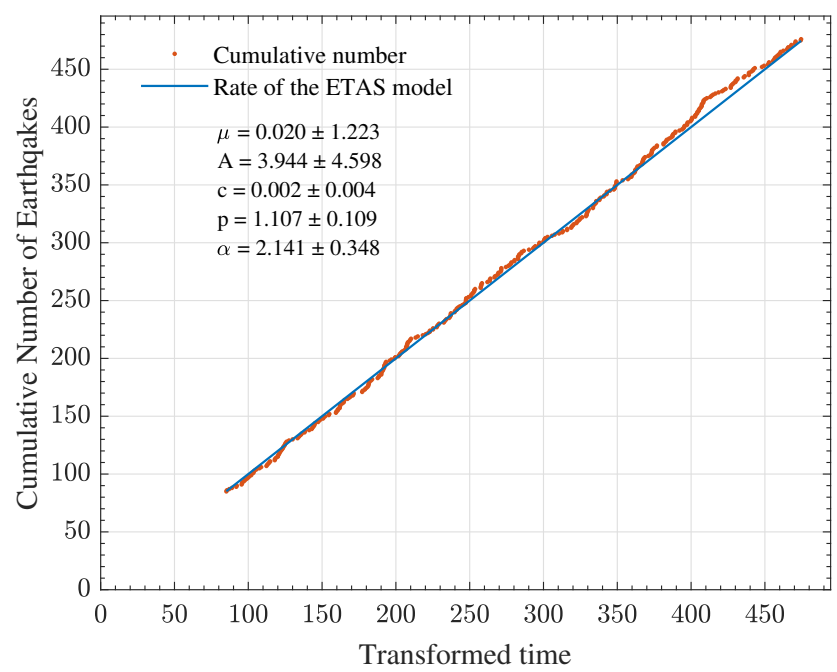

Figure 6. The cumulative number of observed aftershocks in transformed time and corresponding rate of the ETAS model for the 2018, Mw 7.1 Anchorage aftershock sequence with $m \geq 2.8$. The ETAS model fit, Equation (6), for the target time interval of $\left[T_{s}, T_{e}\right]=[0.06,30]$ days is plotted as a solid blue line, and the obtained set of parameters are reported with $95 \%$ confidence intervals.

Finally, the statistical properties of the aftershock sequence initiated by the M7.1 Anchorage, Alaska, earthquake are investigated in detail during several additional target time intervals. Specifically, the sequence was analyzed during several target time intervals starting from the occurrence of the mainshock and ending at $T_{e}=[1,2,3,4,5,6,7,10,14,21,30]$ days. The evolution of the estimated parameters with $95 \%$ confidence intervals for both models OU and ETAS during 2018, Mw 7.1 Anchorage earthquake sequences are shown in Figure A4. Obtained estimations for the $b$-value of the GR relation, Equation (1) with 95\% confidence intervals are demonstrated in Figure A4a. The evolution of the OU model parameters are shown in Figure A4b. We presented the evolution of the estimation of the ETAS model parameters in Figure A4c. 


\subsection{Retrospective Forecasting of the Largest Expected Aftershocks}

In order to calculate the probability of having the magnitude of the largest expected aftershock to be above a certain magnitude and during a predefined forecasting time interval the EVD, Equation (9), and BPD, Equation (12), are used. In this analysis, the OU law, Equation (5), and the ETAS model, Equation (6), are utilized to calculate the aftershock decay rate, and the frequency-magnitude distribution is estimated from the exponential distribution, Equation (3).

To illustrate the applicability of the methods, one particular example is illustrated in case of the 2018 Anchorage sequence. The training time interval was set to $\left[T_{s}, T_{e}\right]=[0.06,14]$ days and the forecasting time interval of $\Delta T=7$ days was considered. The lower magnitude cut-off $m_{0}=2.8$ was used. The computed distributions using the EVD, Equation (9), and BPD, Equation (12) are plotted in Figure 7. For the BPD analysis, total of 20,000 MCMC sampling of the posterior distribution was performed. The first 10,000 iterations were discarded as "burn-in" and the remaining 10,000 samples were utilized to perform stochastic simulations of the ETAS or OU processes. The resulting distributions of the OU and ETAS model parameters estimated from the MCMC chains are reported in Table A1 and plotted in Figures A5 and A6, respectively.

Moreover, two cases are considered for computing the probabilities for the occurrence of the largest expected aftershocks above a certain magnitude during the evolution of the three sequences. For the first case, we considered a constant forecasting time interval $\Delta T=7$ days. As for the target time intervals, we considered the following ending times $T_{e}=[1,2,3,4,5,6,7,10,14,21,30]$ days with the lower magnitude thresholds of 3.0, 3.2, and 2.8 for the 2002, Denali, 2018, Kodiak, and 2018, Anchorage sequences, respectively. In this analysis, the BPD, Equation (12), with the exponential distribution, Equation (3), for the frequency magnitude statistics, and the ETAS model, Equation (6), for the occurrence rate of the earthquakes were utilized. The obtained results for the probabilities of the largest expected earthquakes greater than $m_{\mathrm{ex}} \geq 5.0$, 6.0, 7.0 are shown in Figure 8. Furthermore, the probabilities of having the largest expected aftershock to be above magnitude 6.0 were computed utilizing the EVD, Equation (8), combined with the OU law, Equation (5), and using the BPD, Equation (12), combined with the OU law, Equation (5), or the ETAS model, Equation (6). The obtained results for analyzed mainshocks are presented in Figure 9.

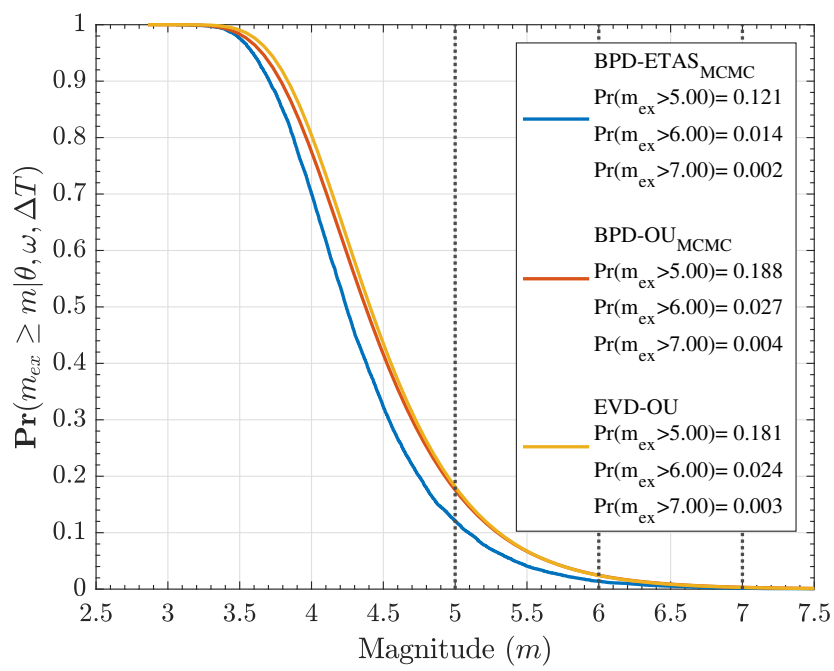

Figure 7. The EVD and BPD for the 2018, Mw 7.1 Anchorage aftershock sequence during the 7-day forecast time interval after the training time interval of 14 days. The blue solid line represents the BPD using the ETAS model with 10000 MCMC sampling steps using the Gamma prior. The orange line represents the obtained BPD using the OU model and the yellow line is the plot of the EVD with the OU law, Equation (11). 


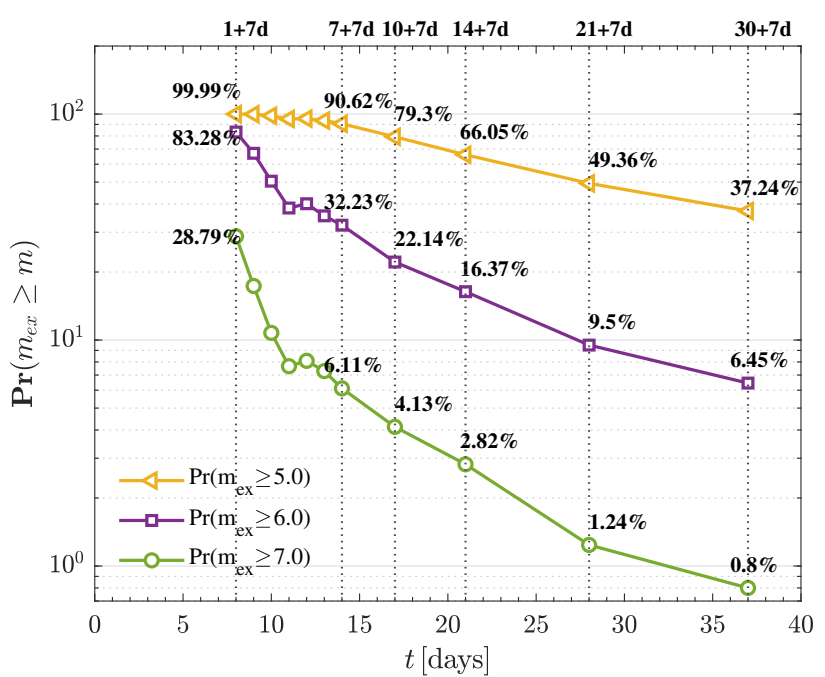

(a)

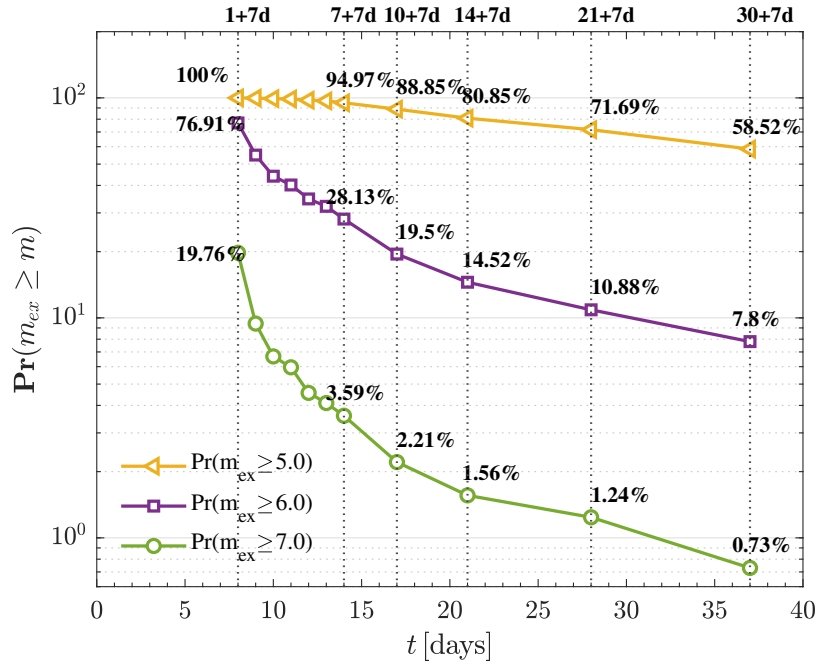

(b)

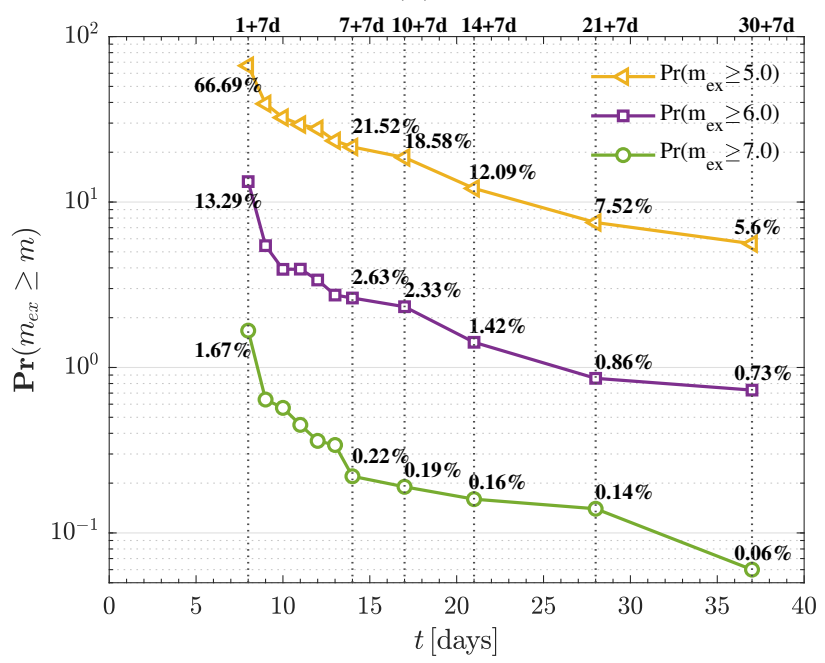

(c)

Figure 8. The probabilities to have the largest expected aftershocks to be larger than $m_{\mathrm{ex}} \geq 5.0,6.0,7.0$ using the BPD, Equation (12), during a constant forecasting time interval $\Delta T=7$ days and for the varying target time intervals. (a) The 3 November 2002, Mw 7.9 Denali sequence with $m \geq 3.0$. (b) The 23 January 2018, Mw 7.9 Kodiak sequence with $m \geq 3.2$. (c) The 30 November 2018, Mw 7.1 Anchorage sequence with $m \geq 2.8$. 


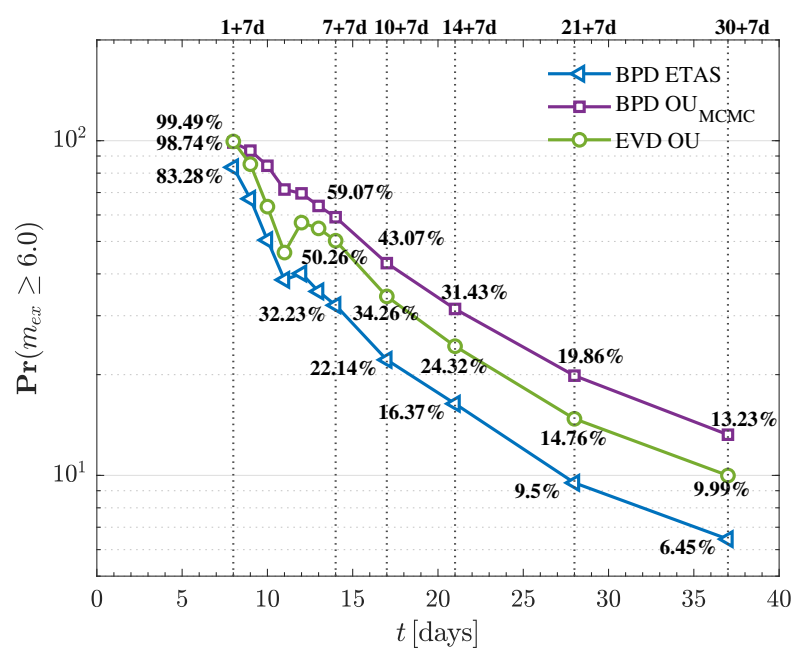

(a)

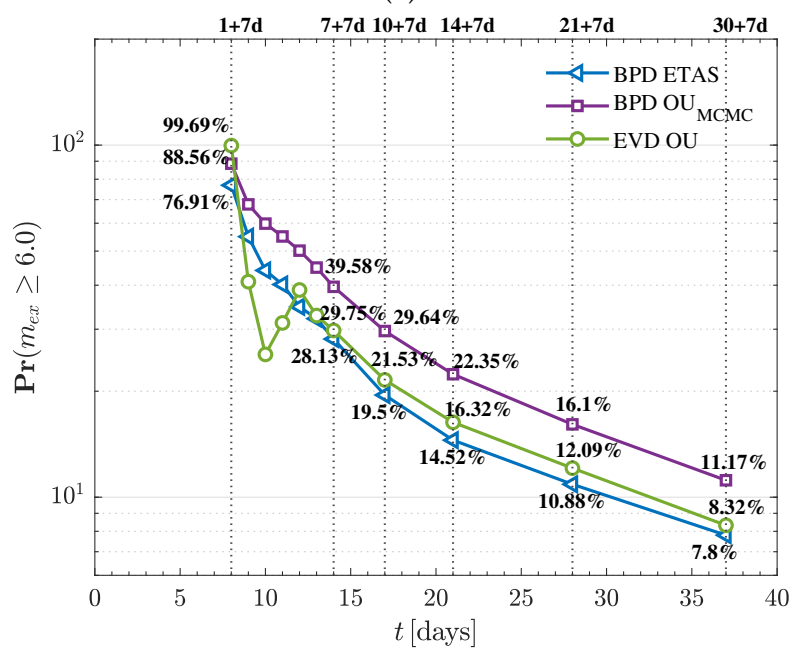

(b)

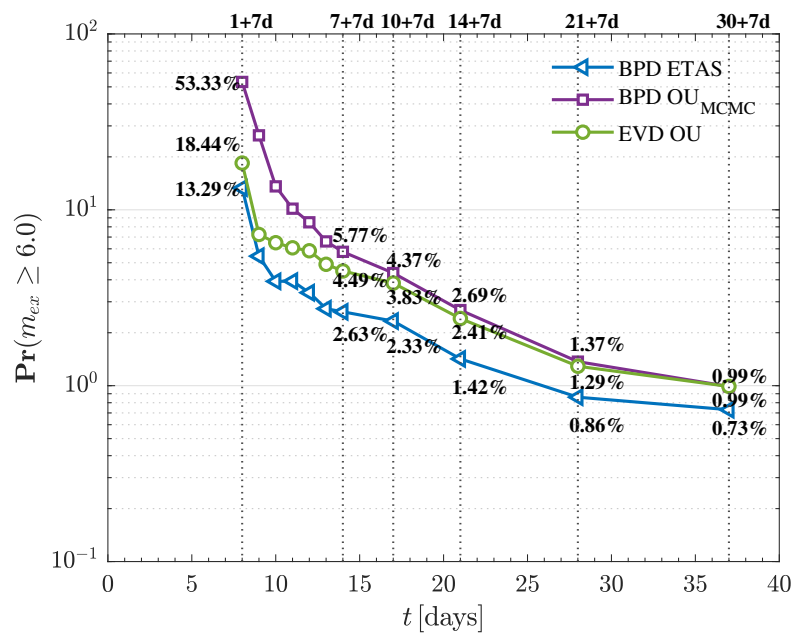

(c)

Figure 9. The comparison of the probabilities to have the largest expected aftershock during the forecasting time interval $\Delta T=7$ days for the three sequences: (a) the 3 November 2002, Mw 7.9 Denali for $m \geq 3.0$; (b) the 23 January 2018, Mw 7.9 Kodiak for $m \geq 3.2$; (c) the 30 November 2018, Mw 7.1 Anchorage for $m \geq 2.8$. The blue triangles are computed using the BPD, Equation (12), with an earthquake decay rate given by the ETAS model, Equation (6). The purple squares are computed using BPD, Equation (12), with an earthquake decay rate given by OU law, Equation (5). The green circles give probabilities computed using the EVD, Equation (11). 
In the second case, a constant target time interval $\left[T_{s}, T_{e}\right]=[0.06,2]$ days was considered. However, the forecasting time interval was varied as $\Delta T=[1,2,5,7,10,14]$ days to compute the probabilities of the occurrence of the largest expected aftershocks. The computed probabilities for the largest anticipated earthquakes $m_{\mathrm{ex}} \geq 5.0,6.0,7.0$ are illustrated in Figure A7. In addition, the comparison of the two approaches to compute the probabilities (EVD versus BPD) combined with either the OU law or the ETAS model are shown in Figure A8.

\subsection{Testing the Model Forecasts}

Several tests were conducted to evaluate the forecast during the time interval $\left[T_{e}, T_{e}+\right.$ $\Delta T$ ] by comparing the simulated results with the observed seismicity. To check the performance of forecasts for the number of aftershocks and magnitude distribution, the $\mathrm{N}$ and M-tests were performed, respectively. The details of the implementation of the tests can be found in Shcherbakov [4].

For the three aftershock sequences the number of forecasted aftershocks in the forecasting time interval $\Delta T=7$ days and using the following target time intervals $T_{e}=$ $[1,2,3,4,5,6,7,10,14,21,30]$ days are given in Figure 10. For comparison, in the same figure the observed number of earthquakes are shown as blue circles for each prediction time interval $\Delta T$. In addition, for the constant target time interval $\left[T_{s}, T_{e}\right]=[0.06,2]$ days and varying forecasting time intervals $\Delta T=[1,2,5,7,10,14]$ days the number of forecasted and observed earthquakes are shown in Figure A9. To investigate the effect of the magnitude cutoff, we also performed the same analysis for earthquakes above magnitude 3.5. This is reported in Figure A10.

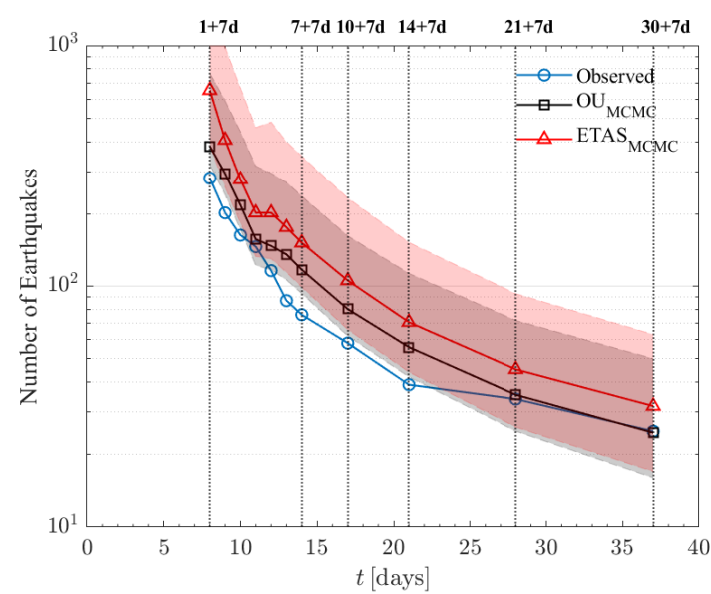

(a)

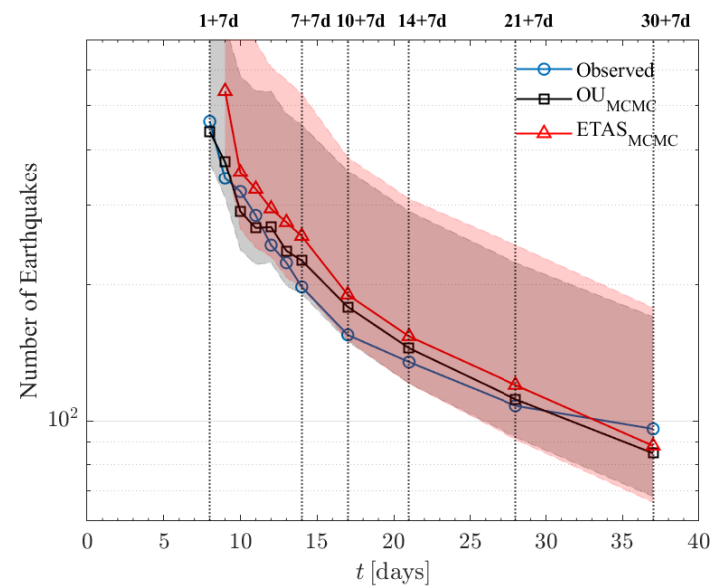

(b)

Figure 10. Cont. 


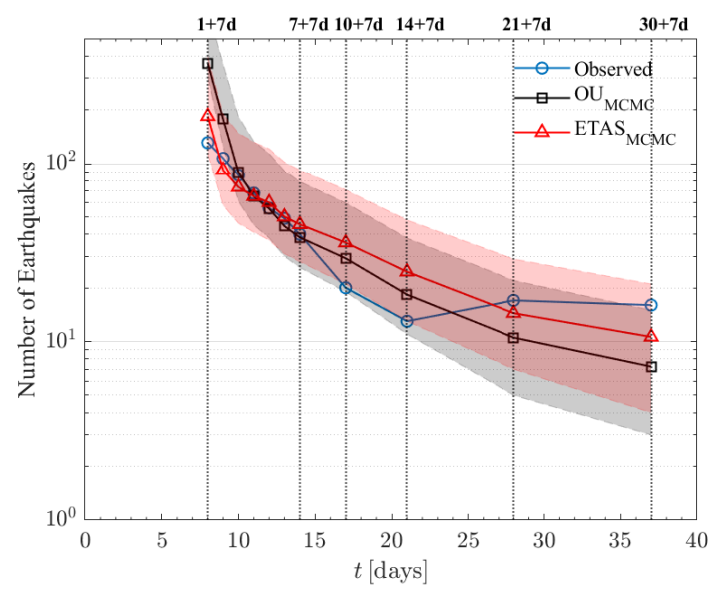

(c)

Figure 10. The number of forecasted and observed aftershocks in the forecasting time interval $\Delta T=7$ days for the three sequences: (a) the 3 November 2002, Mw 7.9 Denali sequence for $m \geq 3.0$; (b) the 23 January 2018, Mw 7.9 Kodiak sequence for $m \geq 3.2$; (c) the 30 November 2018, Mw 7.1 Anchorage sequence for $m \geq 2.8$. The red triangles show the average number of forecasted earthquakes using the ETAS model and the black squares illustrate the average number of forecasted earthquakes using OU law. The shading bands represent $95 \%$ confidence intervals. The blue circles represent the observed number of earthquakes in each forecasting time interval.

In addition, M-test was performed to assess the consistency of the distribution of the magnitudes of the forecasted events. The results of the performance of the OU law and ETAS model are reported by computing the quantile score, $\kappa[4,19] . \kappa$ is defined as the proportion of the forecasted magnitudes compared to the observed magnitudes in each magnitude bin. The obtained quantile scores for the constant forecasting time interval $\Delta T=7$ days are given in Figure 11. In addition, in Figure A11 the outcomes for the M-test for the constant target time interval $\left[T_{s}, T_{e}\right]=[0.06,2]$ days are plotted for the three aftershock sequences.

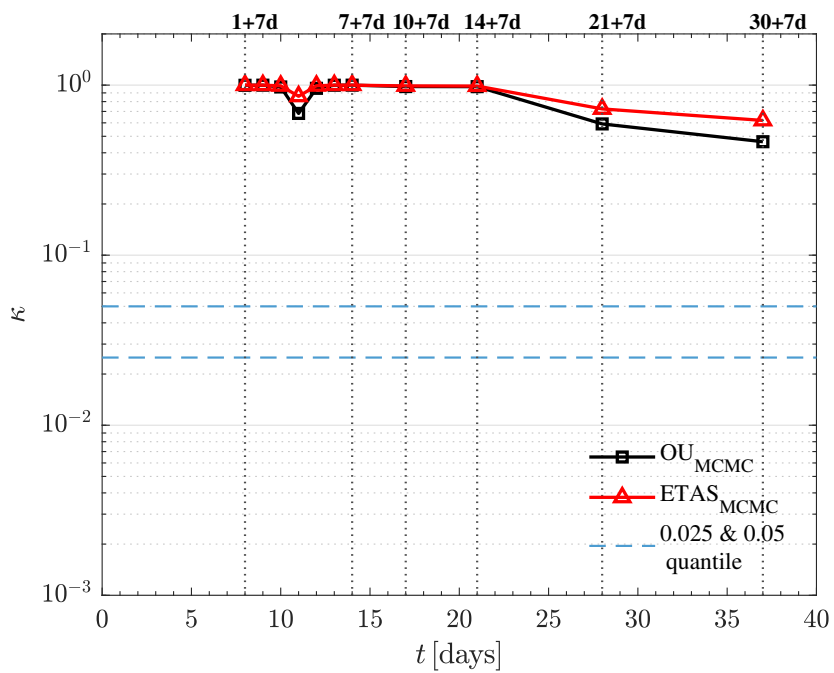

(a)

Figure 11. Cont. 


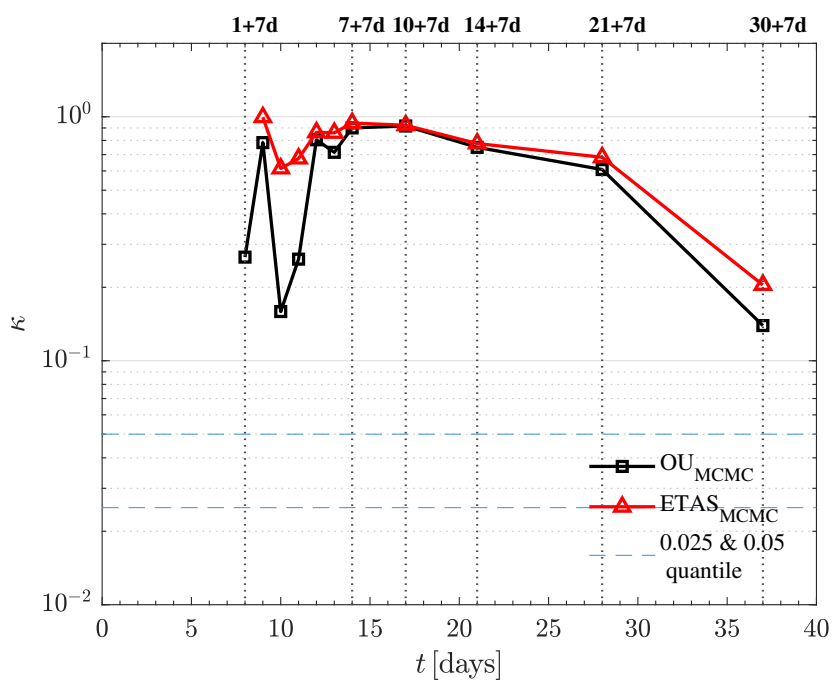

(b)

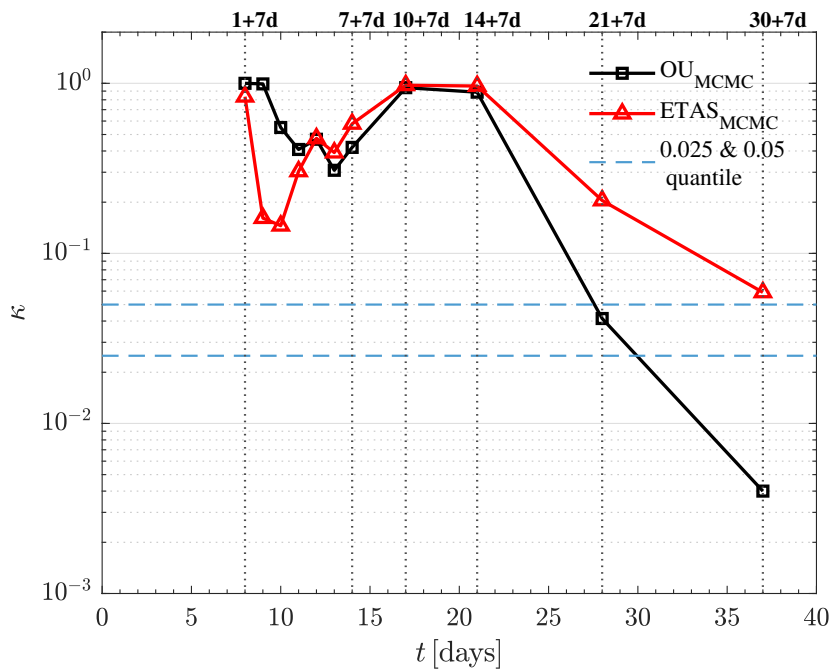

(c)

Figure 11. The obtained quantile scores from the M-test for the constant forecasting time interval $\Delta T=7$ days for the three sequences: (a) the 3 November 2002, Mw 7.9 Denali for $m \geq 3.0$; (b) the 23 January 2018, Mw 7.9 Kodiak for $m \geq 3.2$; (c) the 30 November 2018, Mw 7.1 Anchorage for $m \geq 2.8$. The red triangles demonstrate the obtained quantile scores from the ETAS model and the black squares illustrate the quantile scores of OU law. The blue dashed lines represent the 0.025th and 0.05 th quantiles.

In order to evaluate and compare the models, the R-test and T-test were applied for both cases by considering the ETAS model versus the OU law. In the R-test the quantile score, $\alpha$, was calculated. $\alpha$ is the proportion of the simulated likelihood ratios, over the observed likelihood ratios [17]. The values of $\alpha$ that are greater than a specific level of significance support the model that was chosen as a base model, in this case it is the ETAS model. The obtained result for the $\alpha$ from the OU law versus the ETAS model is shown in Figure 12. Furthermore, in Figure 13, the ratio of the likelihood score of the ETAS model and the OU law over the number of the observed events in the forecasting time interval is given. The T-test is used to assess whether the sample information gain is statistically different from zero. This is used to select the preferred model [49]. Lastly, the Bayesian $p$-value of the BPD analysis using either the ETAS model or the OU law are illustrated for both cases in Figure 14. 


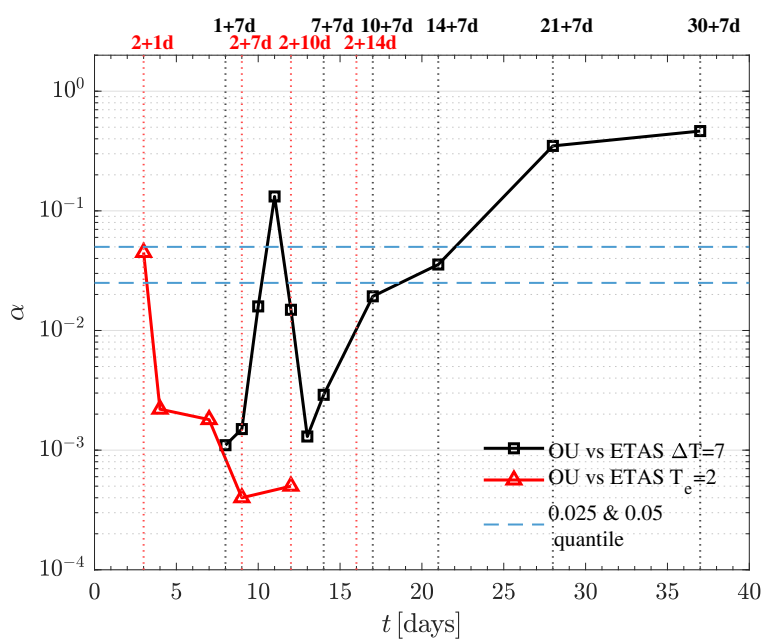

(a)

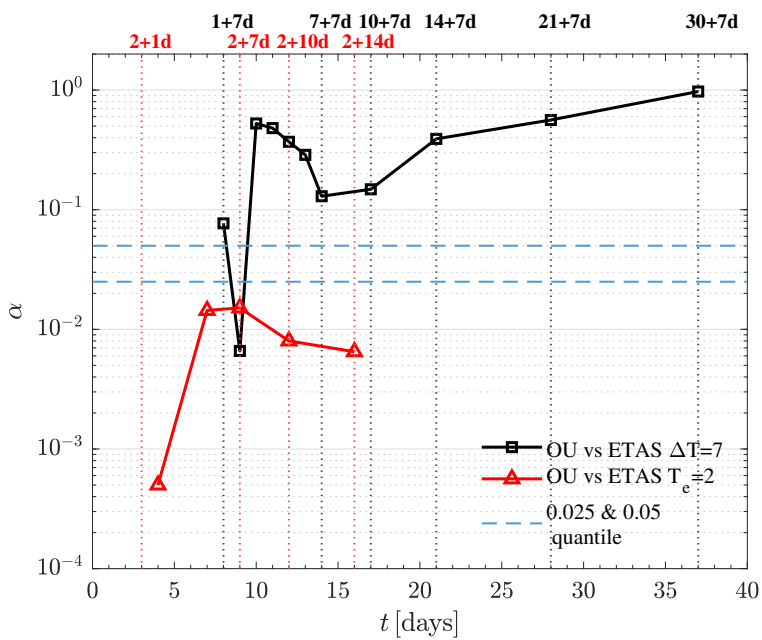

(b)

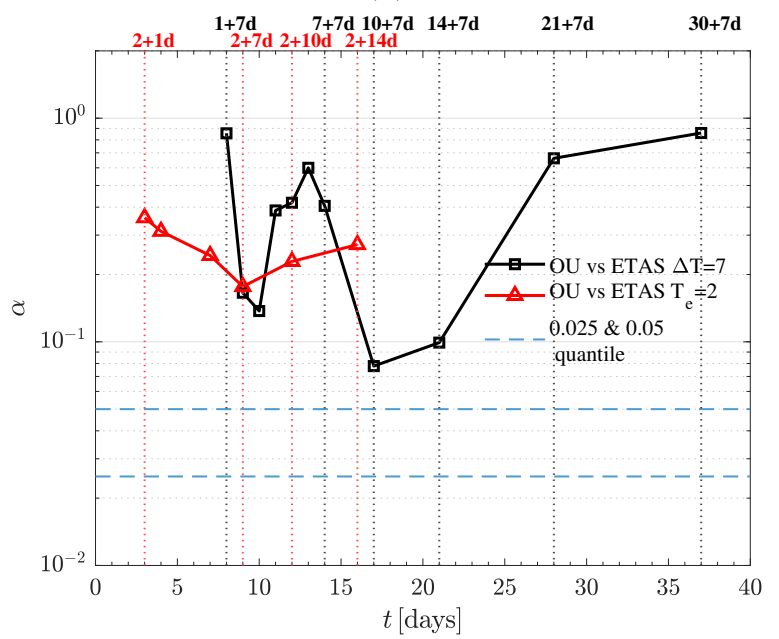

(c)

Figure 12. The obtained quantile scores from the R-test to compare the forecast based on the OU law versus the ETAS model for the three sequences: (a) the 3 November 2002, Mw 7.9 Denali for $m \geq 3.0$; (b) the 23 January 2018, Mw 7.9 Kodiak for $m \geq 3.2$; (c) the 30 November 2018, Mw 7.1 Anchorage for $m \geq 2.8$. The black squares illustrate the quantile scores in the case with the constant forecasting time interval of $\Delta T=7$ days. The red triangles show the obtained quantile scores from the second case with the constant target time interval of $\left[T_{s}, T_{e}\right]=[0.06,2]$ days. The blue dashed lines represent the 0.025 th and 0.05 th quantiles. 


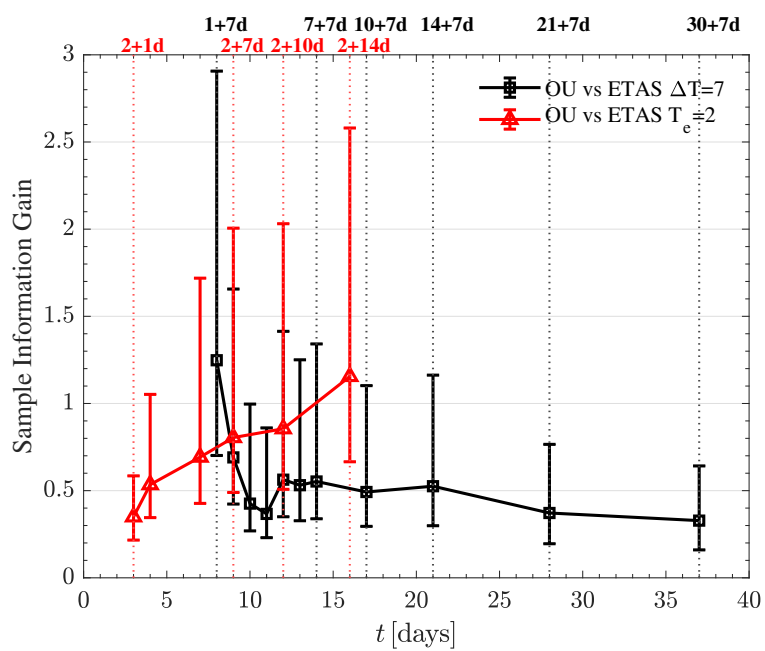

(a)

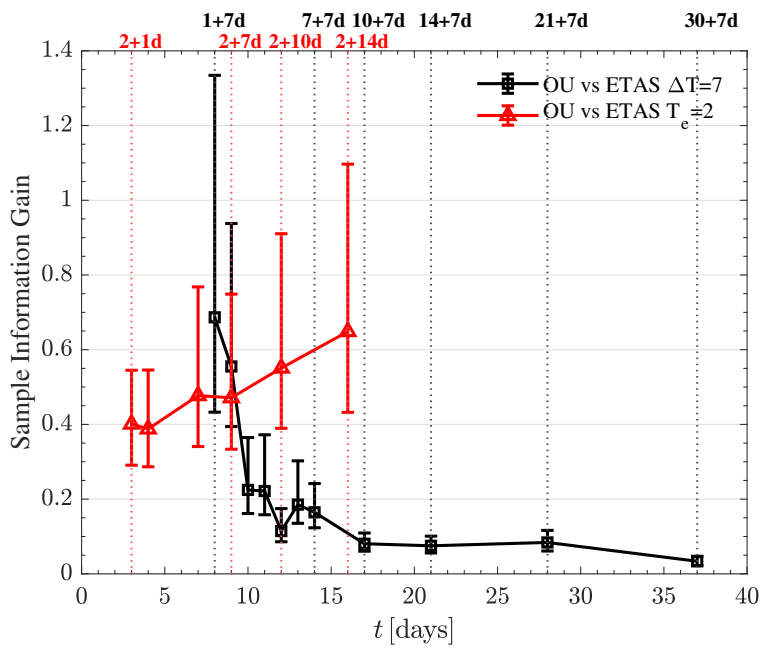

(b)

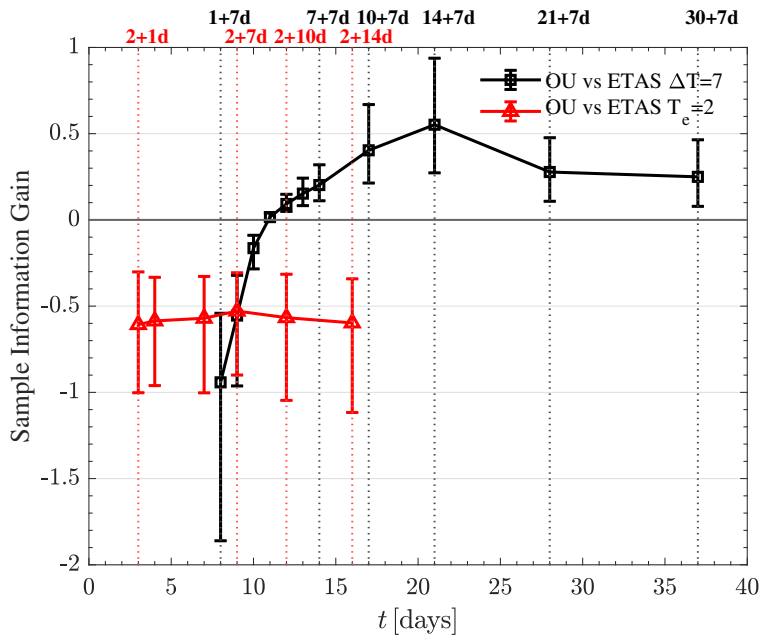

(c)

Figure 13. The sample information gain of the ETAS model versus the OU law over the number of observed data for the three sequences: (a) the 3 November 2002, Mw 7.9 Denali for $m \geq 3.0$; (b) the 23 January 2018, Mw 7.9 Kodiak for $m \geq 3.2$; (c) the 30 November 2018, Mw 7.1 Anchorage for $m \geq 2.8$. The black solid squares illustrate the sample information gain for the first case with the fixed the forecasting time interval of $\Delta T=7$ days. The red triangles demonstrate the sample information gain for the second case for the constant target time interval $\left[T_{s}, T_{e}\right]=[0.06,2]$ days. 


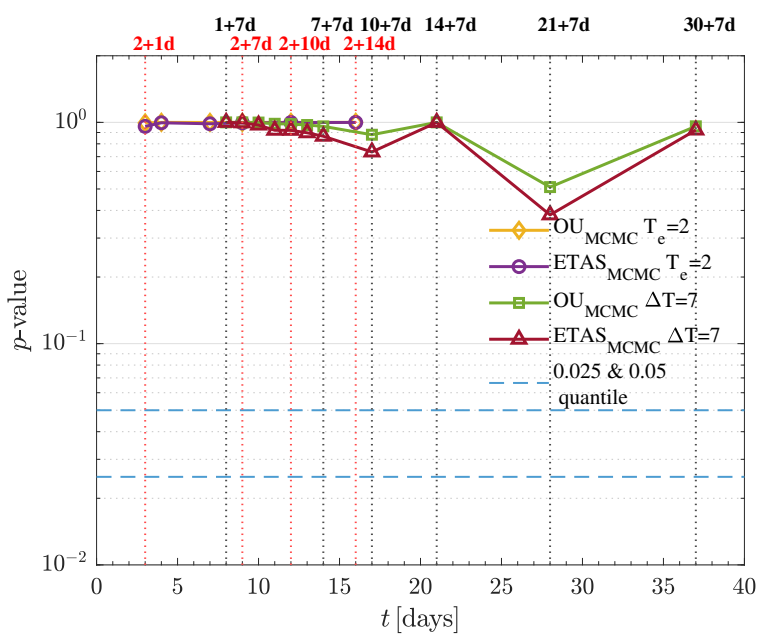

(a)

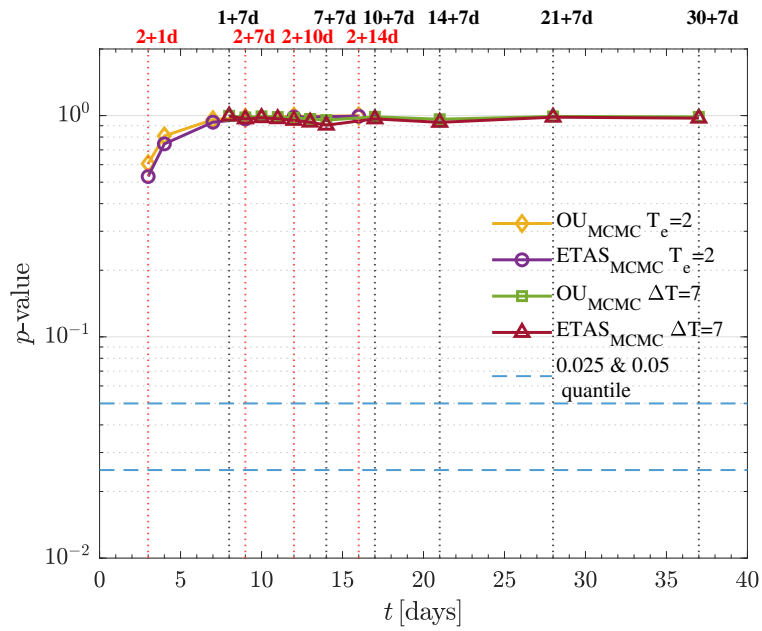

(b)

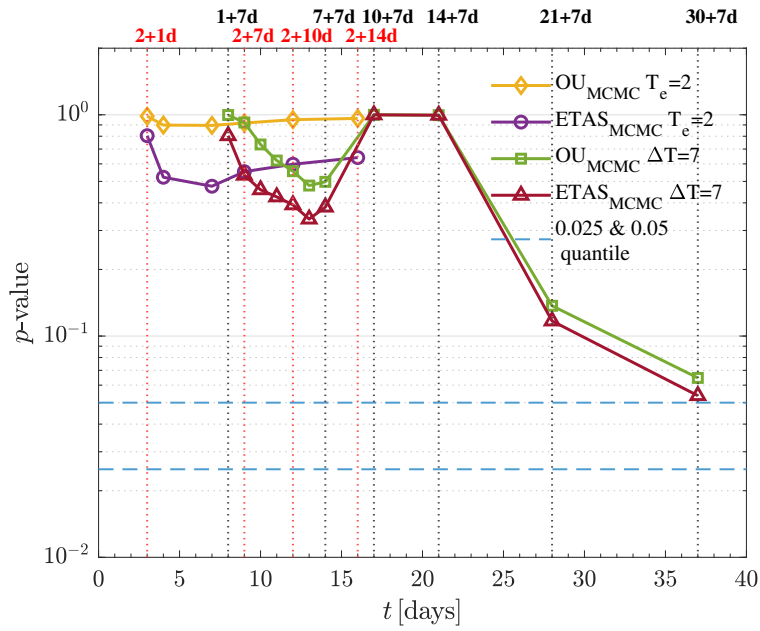

(c)

Figure 14. For both cases the Bayesian $p$-value of the BPD from the ETAS model and the OU law are illustrated for the three sequences: (a) the 3 November 2002, Mw 7.9 Denali for $m \geq 3.0$; (b) the 23 January 2018, Mw 7.9 Kodiak for $m \geq 3.2$; (c) the 30 November 2018, Mw 7.1 Anchorage for $m \geq 2.8$. The green squares and the red triangles illustrate the obtained $p$-value from the first case, with the fixed forecasting time interval $\Delta T=7$ days. The yellow diamonds and purple circles demonstrate the $p$-value for the second case with the constant target time interval of $\left[T_{s}, T_{e}\right]=[0.06,2]$ days. The blue dashed lines represent the 0.025 th and 0.05 th quantiles. 


\section{Discussion and Conclusions}

To describe the three aftershock sequences which occurred in the Alaska region, statistical models were used in this study. To be more precise, the frequency-magnitude statistical analysis was performed using the GR relation, and the occurrence rates of the aftershock sequence were estimated by the OU law and the ETAS model. The EVD and BPD approaches were used to calculate the probability of having the largest expected aftershock above a certain magnitude during evolution of each sequence for various training and forecasting time intervals.

The frequency-magnitude distributions and estimated GR parameters for analyzed sequences are shown in Figure 3. The frequency-magnitude distribution of the Denali aftershock sequence, was characterized by a broad distribution of event magnitudes which led to a relatively low $b$-value $(0.749 \pm 0.053)$ (Figure 3$)$. The 2002, Denali mainshock was followed by several large aftershocks with the largest being 5.6 magnitude which occurred in the first $24 \mathrm{~h}$ after the mainshock. The frequency-magnitude statistical analysis of the aftershock sequence of the Kodiak 7.9 magnitude earthquake with the cut-off magnitude 3.2 for the target time interval $\left[T_{s}, T_{e}\right]=[0,30]$ days was performed (Figure 3). The frequencymagnitude distribution of the 2018, Kodiak sequence indicates a typical GR fit with $b$-value $(1.035 \pm 0.059)$. The mainshock was followed by several large aftershocks with the largest being 5.5 magnitude event. It should be noted the epicenter of the 2018, Kodiak earthquake was located in a remote area in the North Pacific. The analysis of the 2018 Anchorage sequence produced the $b$-value of $0.906 \pm 0.082$ (Figure 3). The largest aftershock with a magnitude 5.8, was close to the expected magnitude from Båth's law [5] which states that the largest aftershock is on average 1.2 magnitudes lower than the mainshock.

In order to analyze the occurrence rate of the aftershock sequence of the selected mainshocks, the Omori-Utsu law, Equation (5), and the ETAS model, Equation (6), were utilized. The obtained results from the analysis of the decay rate of the aftershock sequences show that the parameter $p$ is comparable for both models (the OU law and the ETAS model) except for the 2018 Kodiak sequence.

Computing the probability of having a largest expected aftershock with a magnitude above a given value during different forecasting time intervals after the mainshock was one of the main objectives of this work. The EVD and BPD approaches were used to accomplish this objective.

The obtained result of this analysis indicates that the BPD method using the ETAS model is more conservative than BPD using the OU law and the EVD approach. In addition, for the aforementioned approaches, the probabilities of having an earthquake with magnitude 6 and above were calculated for both cases (Figures 9 and A8).

Moreover, in order to compare characteristics of analyzed sequences the probabilities to have the largest expected aftershocks to be larger than $m_{\mathrm{ex}} \geq 5.0,6.0,7.0$ were estimated by using the BPD, Equation (12), for both cases (Figures 8 and A7). The results of this analysis show that the Anchorage sequence had a lower potential to generate aftershocks with $m_{\text {ex }} \geq 5.0,6.0,7.0$ compared to other analyzed sequences. These statistical results can be explained directly by the number of events in the aftershock sequence and the magnitude of the mainshock. This increases the probability of occurrence of an aftershock with a certain magnitude in a predefined time interval after the mainshock. In the present implementation of the EVD and BPD analysis we used the unbounded GR distribution. It was suggested that more realistic truncated magnitude distribution can be more appropriate for forecasting $[52,53]$. This can be easily incorporated in the analysis as well.

The N-tests, M-test, R-test, and T-test were performed to evaluate the goodness of the models' results in the forecasting time interval $\left[T_{e}, T_{e}+\Delta T\right]$ by comparison of the simulated results and observed seismicity. The number of the forecasted earthquakes was evaluated by the $\mathrm{N}$-test and the results are shown in Figures 10 and A9 for both cases. In both cases, for the Anchorage sequence, a more accurate forecast for the number of earthquakes was accomplished by the ETAS model, while for two other sequences the OU law performed better. It should be noted as a result of the branching nature of the ETAS model, it shows a 
wider confidence interval range compared to the OU law. The obtained results from the M-test demonstrate higher consistency in generating the distribution of the magnitudes for the ETAS model compared to the OU law for both cases, Figures 11 and A11. For the model comparison, the R-test was performed (Figure 12). The $\alpha$ quantile score is higher than the thresholds representing the rejection of the OU hypothesis in favor of the ETAS model. The T-test results are given in Figure 13. The ETAS model performed better in case of the Denali and Kodiak sequences, however, the OU model was more accurate in estimating the rate and the corresponding forecasting performance in case of the Anchorage sequence in its early days. This is also evident when plotting the information gain both for the fixed forecasting time interval $\Delta T=7$ days with varying training time intervals and in case of the fixed training time interval with varying forecasting time intervals (Figure 13c). The posterior predictive $p$-value test was performed to assess the fit of the posterior distribution of Bayesian models by comparison of the posterior predictive distribution and the observed data. In Figure 14 the results of Bayesian p-value analysis are given. They indicate that the forecasts based both on the ETAS model and OU formula are consistent in reproducing the maximum event during each corresponding forecasting time interval.

The obtained results indicate that for the sequences analyzed the forecasting based on the ETAS model and the OU formula produce comparable results for shorter time intervals after the mainshocks. However, the EAST model is more realistic in terms of reproducing the seismicity on longer time scales. Moreover, the ETAS model performs better when the mainshock sequence is preceded by a well defined foreshock sequence [3].

The ETAS model typically performs better with increased number of events in the sequence. However, this is limited by the current earthquake catalogues which typically have relatively high level of completeness that results in fewer events.

Author Contributions: Conceptualization, M.S. and R.S.; methodology, M.S. and R.S.; software, M.S. and R.S.; validation, M.S. and R.S.; writing—original draft preparation, M.S.; writing-review and editing, R.S.; visualization, M.S. and R.S.; supervision, R.S.; project administration, R.S.; funding acquisition, R.S. All authors have read and agreed to the published version of the manuscript.

Funding: M.S. and R.S. would like to acknowledge the support from the UWO IDI grant. R.S. was partially supported by NSERC Discovery grant.

Institutional Review Board Statement: Not applicable.

Informed Consent Statement: Not applicable.

Data Availability Statement: The United States Geological Survey (USGS) search engine was used to extract the earthquake catalogue https: / / earthquake.usgs.gov/ earthquakes/search/ (accessed on 18 December 2021). The United States Geological Survey (USGS), was used to obtain the Quaternary fault and fold database for the United States [33]. The mainshock focal mechanism was obtained from the USGS Moment Tensor catalogue [34-36]. The data analysis was performed using a computer code written in Matlab and can be requested from the author.

Acknowledgments: The authors would like to thank Matteo Taroni and two other anonymous reviewers for their useful and constructive comments that helped to improve the paper.

Conflicts of Interest: The authors declare no conflict of interest.

\author{
Abbreviations \\ The following abbreviations are used in this manuscript: \\ BPD Bayesian Predictive Distribution \\ CSEP Collaboratory for the Study of Earthquake Predictability \\ ETAS Epidemic Type Aftershock Sequence \\ EVD Extreme Value Distribution \\ GFT Goodness of Fit Test \\ GR Gutenberg-Richter \\ MCMC Markov Chain Monte Carlo
}


MLE Maximum Likelihood Estimation

OU Omori-Utsu

USGS United States Geological Survey

\section{Appendix A}

Table A1. Forecast model parameters distribution from 10,000 MCMC sampling for 2018, Anchorage sequence.

\begin{tabular}{ccccc}
\hline Model & Parameter & Mean & Std & $\mathbf{9 5 \% ~ C I ~}$ \\
\hline Omori-Utsu law, Equation (5), & $\beta$ & 2.077 & 0.093 & {$[1.897,2.261]$} \\
with Exponential frequency & $K$ & 144.3 & 2.838 & {$[138.8,149.7]$} \\
magnitude distribution, & $c$ & 0.220 & 0.019 & {$[0.185,0.261]$} \\
Equation (3), & $p$ & 1.4 & 0.046 & {$[1.311,1.491]$} \\
\hline ETAS model, Equation (6), & $\beta$ & 2.28 & 0.11 & {$[2.07,2.50]$} \\
with Exponential frequency & $\mu$ & 0.001 & 0.0003 & {$[0.0004,0.0017]$} \\
magnitude distribution, & $A$ & 0.104 & 0.03 & {$[0.06,0.16]$} \\
Equation (3), & $c$ & 0.028 & 0.008 & {$[0.013,0.045]$} \\
& $p$ & 1.113 & 0.034 & {$[1.048,1.184]$} \\
& $\alpha$ & 2.42 & 0.097 & {$[2.257,2.659]$} \\
\hline
\end{tabular}

(a)

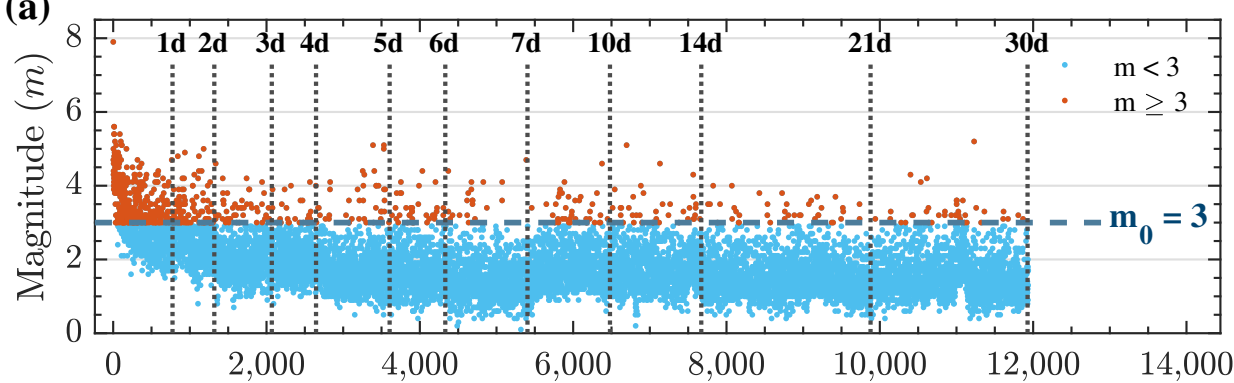

(b)

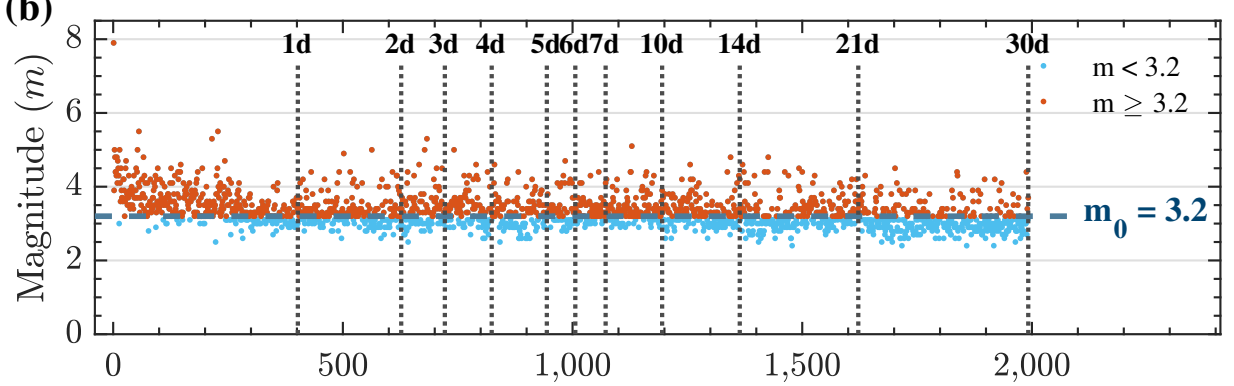

(c)

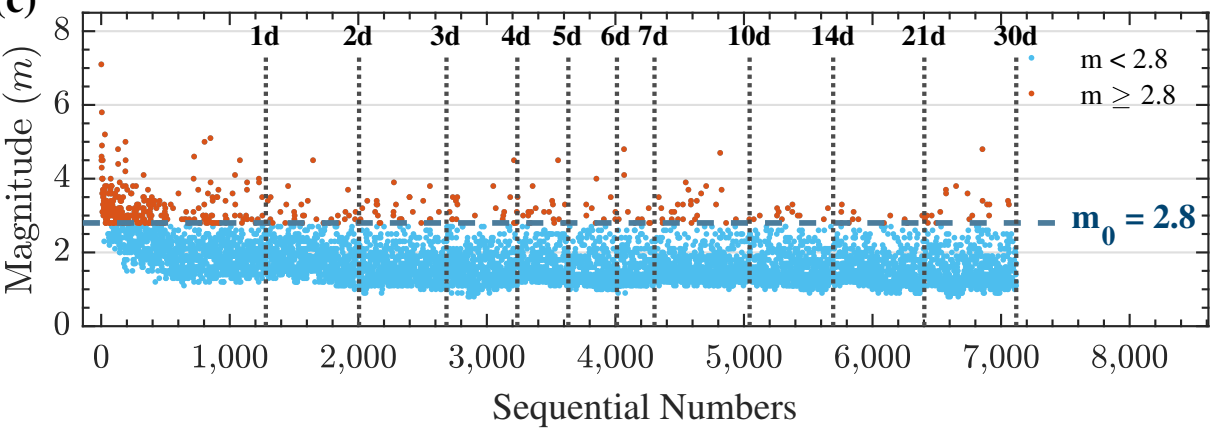

Figure A1. Plot of the magnitudes versus sequential numbers of the earthquakes in the study regions for the three sequences: (a) 3 November 2002, Mw 7.9 Denali (b) 23 January 2018, Mw 7.9 Kodiak (c) 30 November 2018, Mw 7.1 Anchorage. The corresponding times in days after each mainshock are depicted by doted vertical lines. 


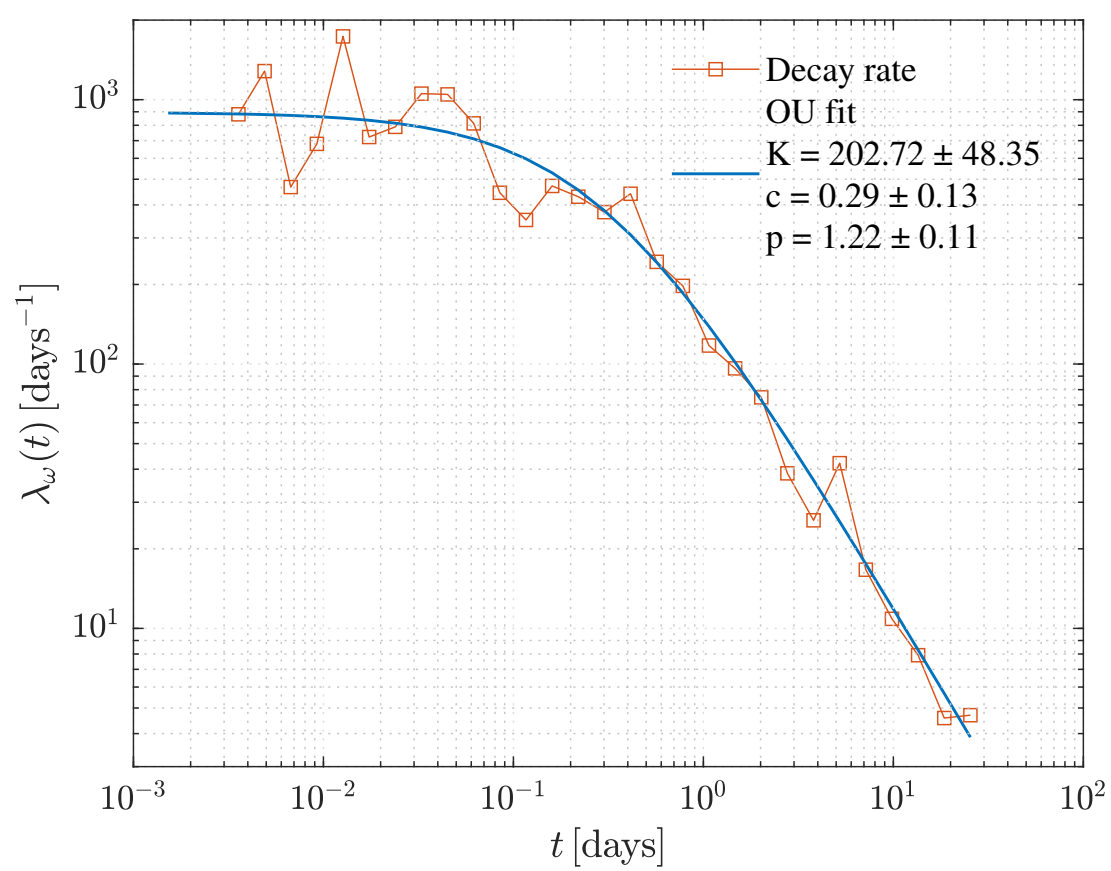

(a)

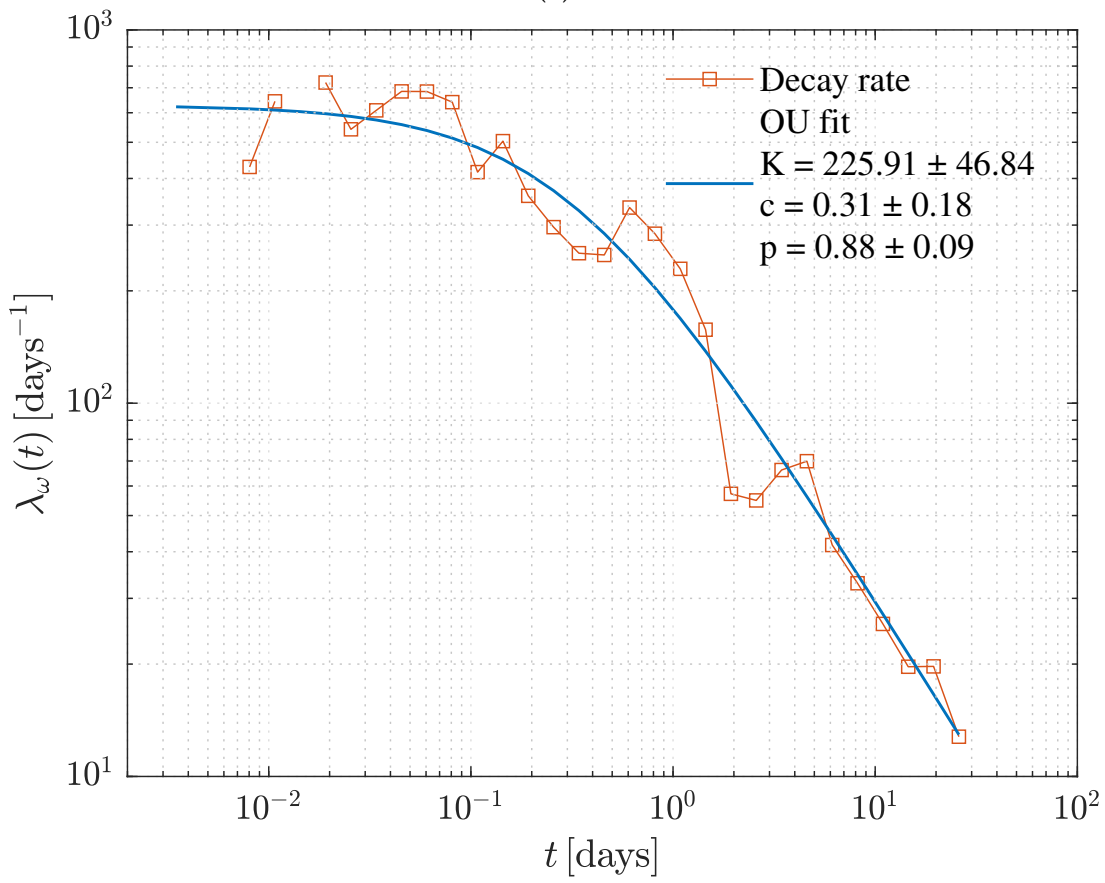

(b)

Figure A2. The log-log plot of the earthquake decay rates for: (a) the 2002, Mw 7.9 Denali sequence with $m \geq 3.0$; (b) the 2018, Mw 7.9 Kodiak sequence with $m \geq 3.2$ are presented as open squares. The blue solid lines are the corresponding fit of the OU law, Equation (5), to the aftershock sequences. The obtained parameters from the OU law, Equation (5), with the $95 \%$ confidence intervals are reported in the legends. 


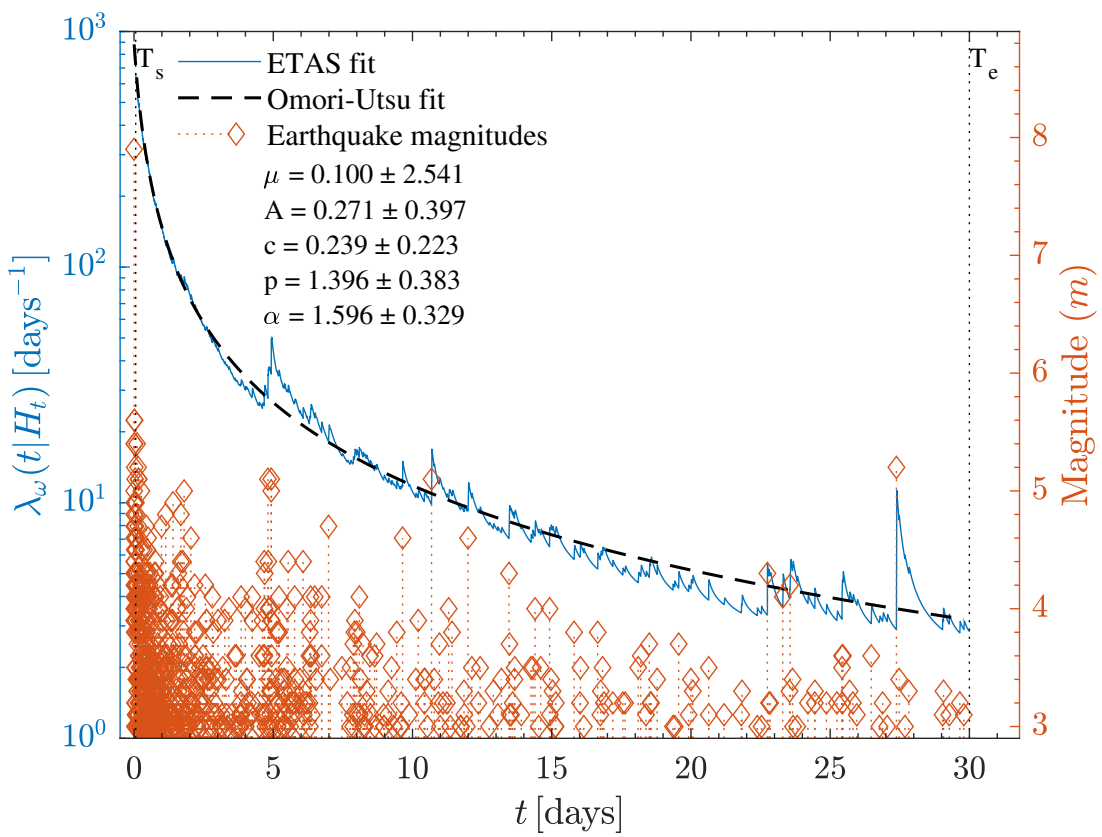

(a)

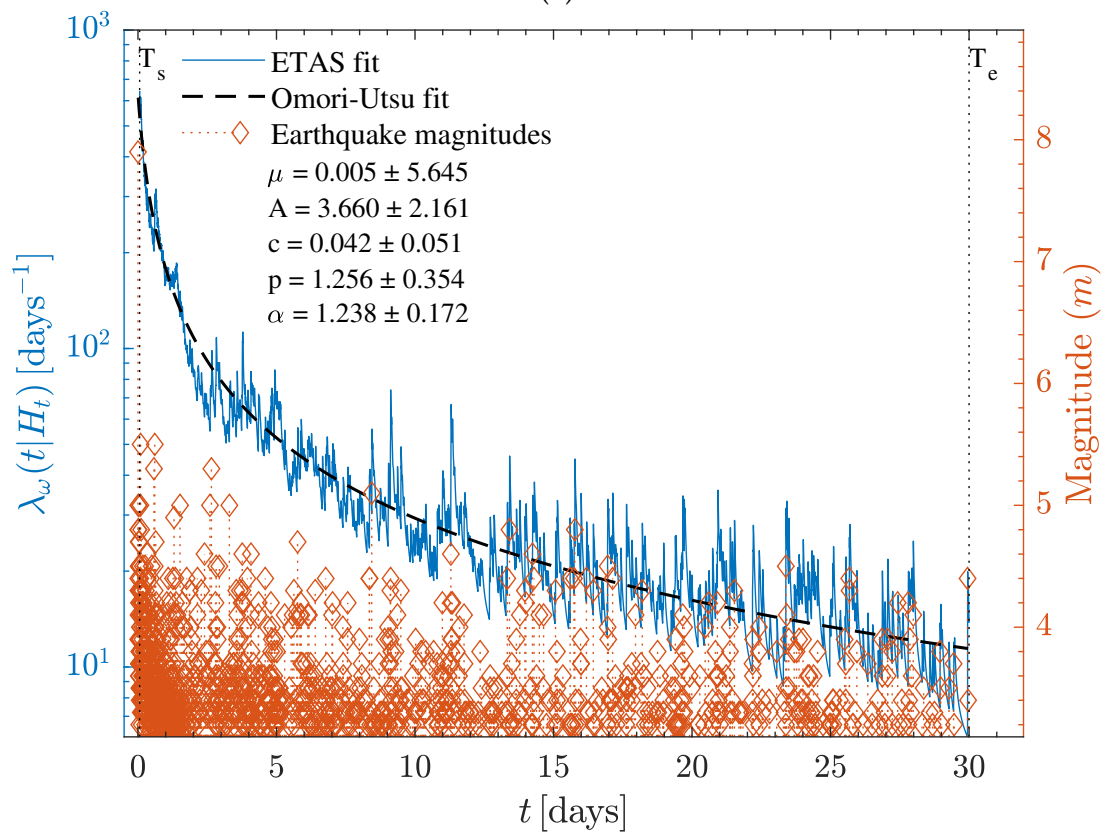

(b)

Figure A3. The aftershock sequence and corresponding earthquake magnitude for: (a) the 2002, Mw 7.9 Denali sequence with $m \geq 3.0$; (b) the 2018, Mw 7.9 Kodiak sequence with $m \geq 3.2$. The ETAS model fit, Equation (6), for the target time interval of $\left[T_{s}, T_{e}\right]=[0.06,30]$ is plotted as a solid blue line, and the obtained set of parameters are reported with $95 \%$ confidence intervals. The OU law fit, Equation (5), is plotted as a black dashed line for comparison. 
(a)
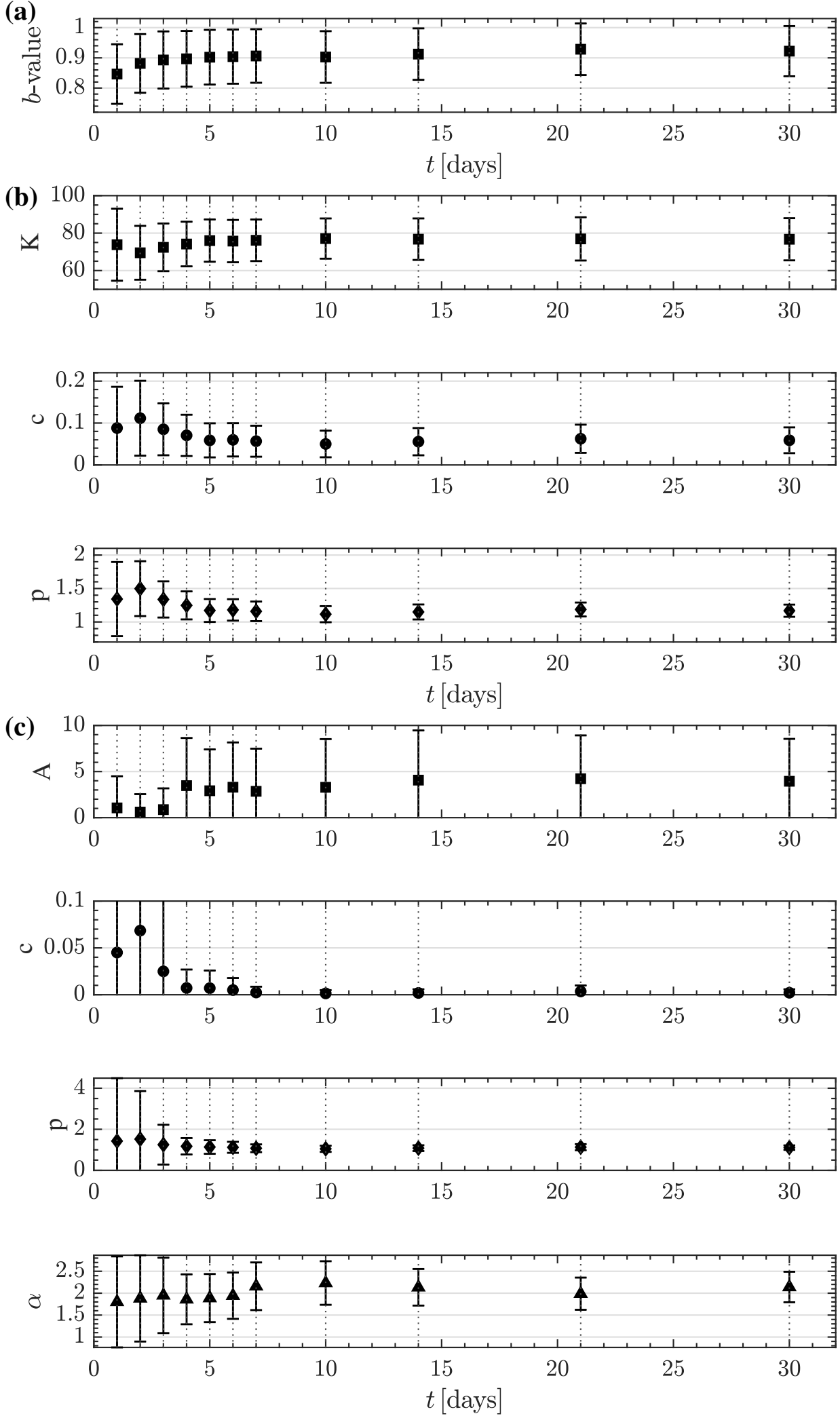

Figure A4. The model parameter estimation during the aftershock sequence of the 2018, Anchorage for all the events with magnitude 2.8 and greater. (a) The estimated $b$-value, Equation (1), (b) the parameters $\{K, c, p\}$ of the OU law, Equation (5), and (c) the parameters $\{A, c, p, \alpha\}$ of the ETAS model, Equation (6). The error bars represent the $95 \%$ confidence intervals during the target time intervals, $\{1,2,3,4,5,6,7,10,14,21,30\}$, days after the mainshock. 


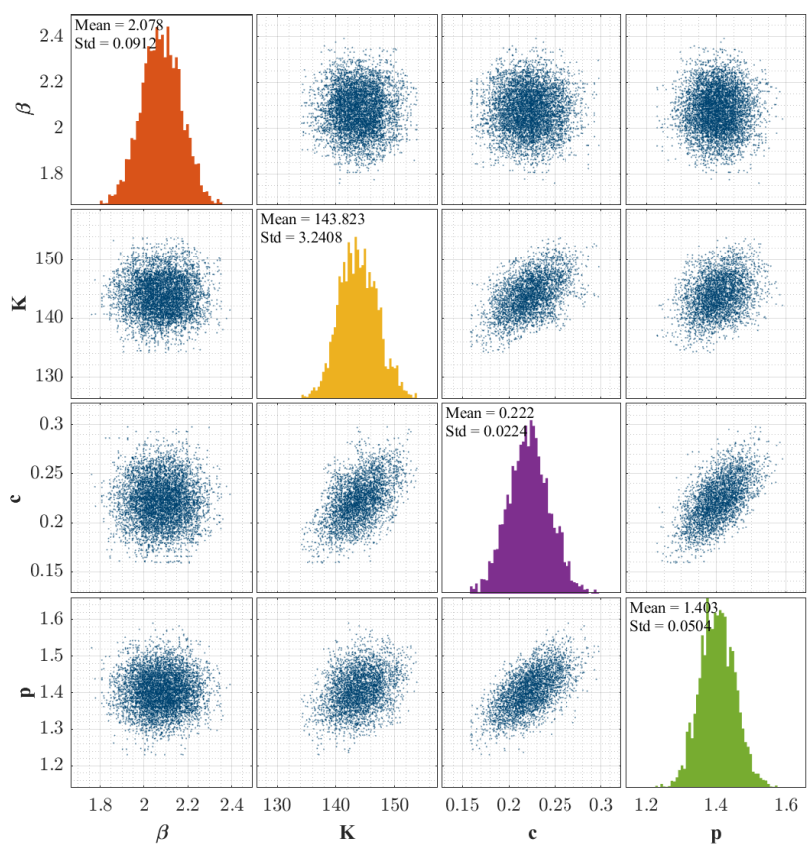

Figure A5. The distribution of each parameter and the matrix plot of the pairs of the OU parameters that computed using the MCMC sampling for the 2018, Mw 7.1 Anchorage sequence with $m \geq 2.8$.

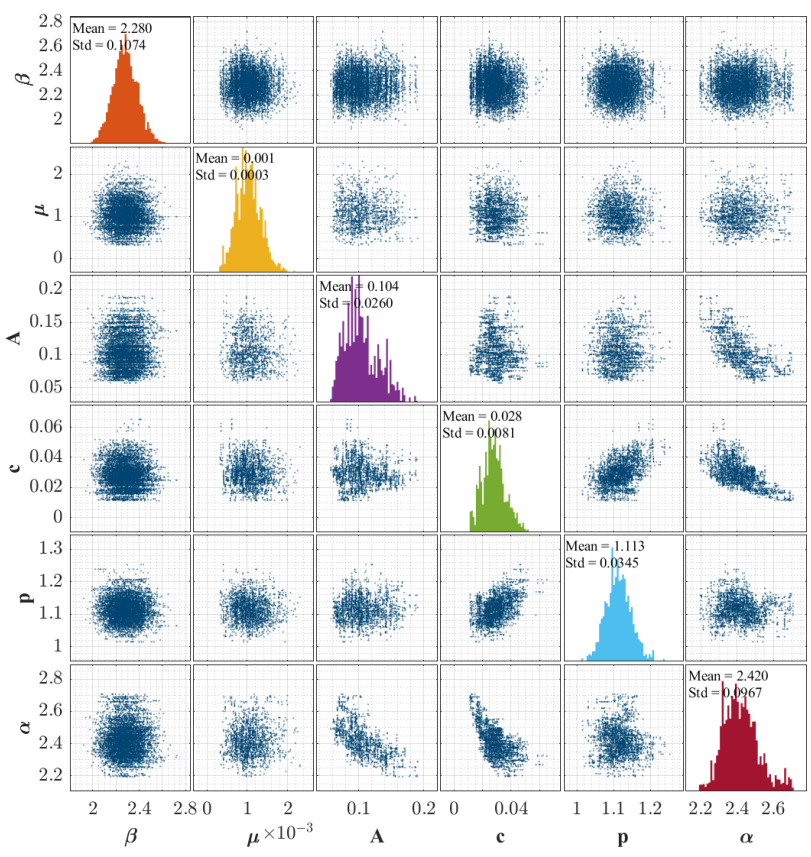

Figure A6. The distribution of each parameter and the matrix plot of the pairs of the ETAS parameters computed using the MCMC sampling for the 2018, Mw 7.1 Anchorage sequence with $m \geq 2.8$. 


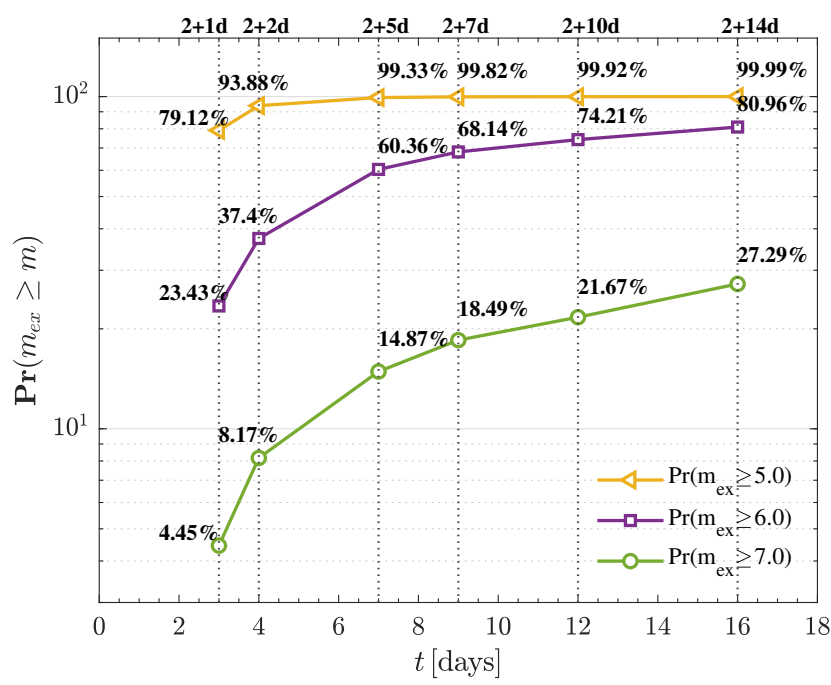

(a)

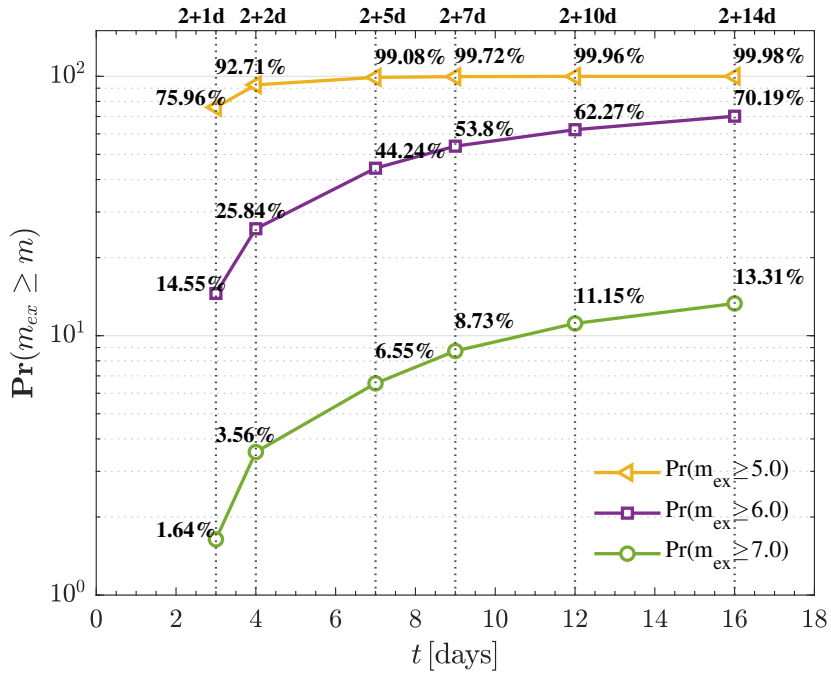

(b)

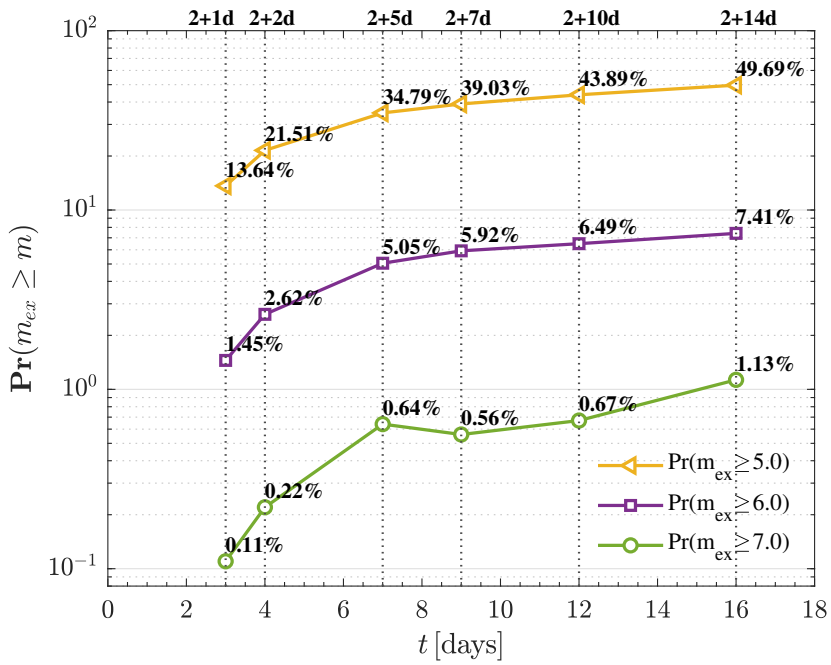

(c)

Figure A7. The probabilities to have the largest expected aftershocks to be larger than $m_{\mathrm{ex}} \geq 5.0$, 6.0, 7.0 using the BPD, Equation (12), during a constant target time interval of $\left[T_{s}, T_{e}\right]=[0.06,2]$ days and for the varying target time intervals. (a) The 3 November 2002, Mw 7.9 Denali sequence with $m \geq 3.0$. (b) The 23 January 2018, Mw 7.9 Kodiak sequence with $m \geq 3.2$. (c) The 30 November 2018, Mw 7.1 Anchorage sequence with $m \geq 2.8$. 


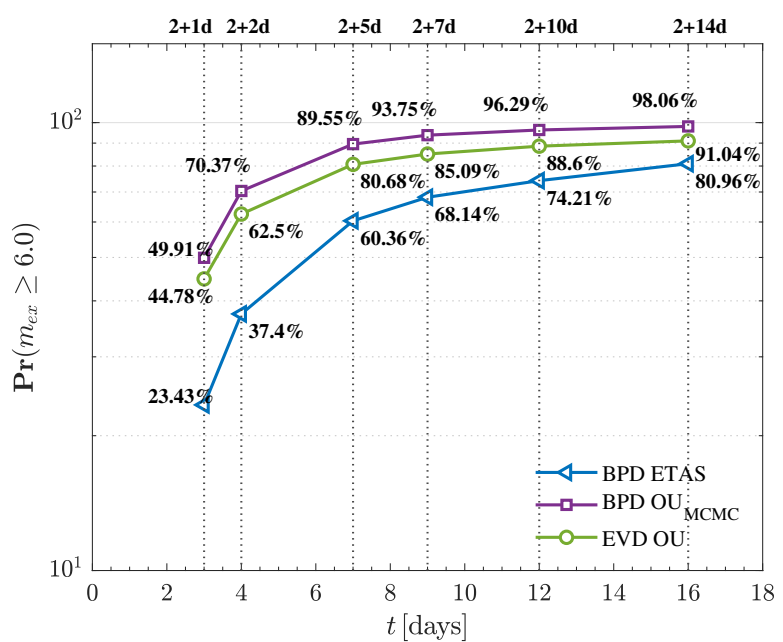

(a)

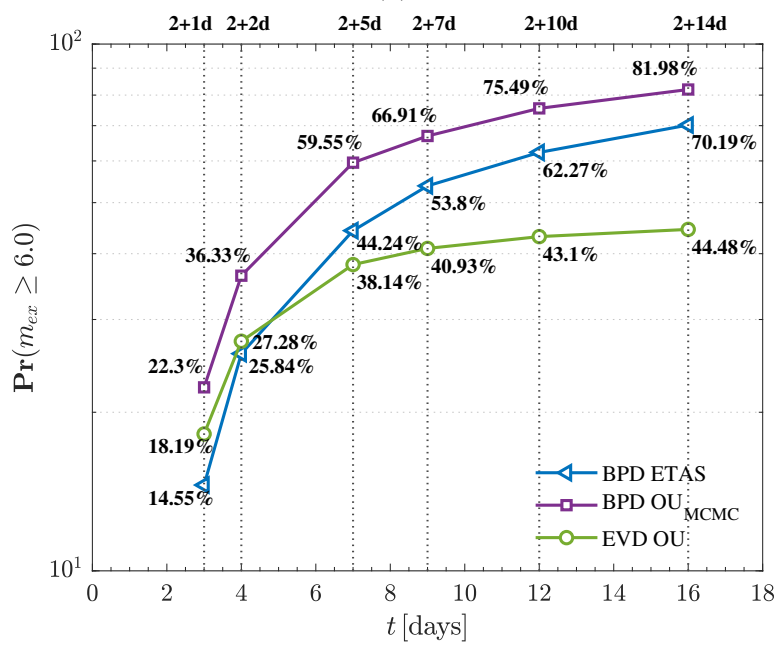

(b)

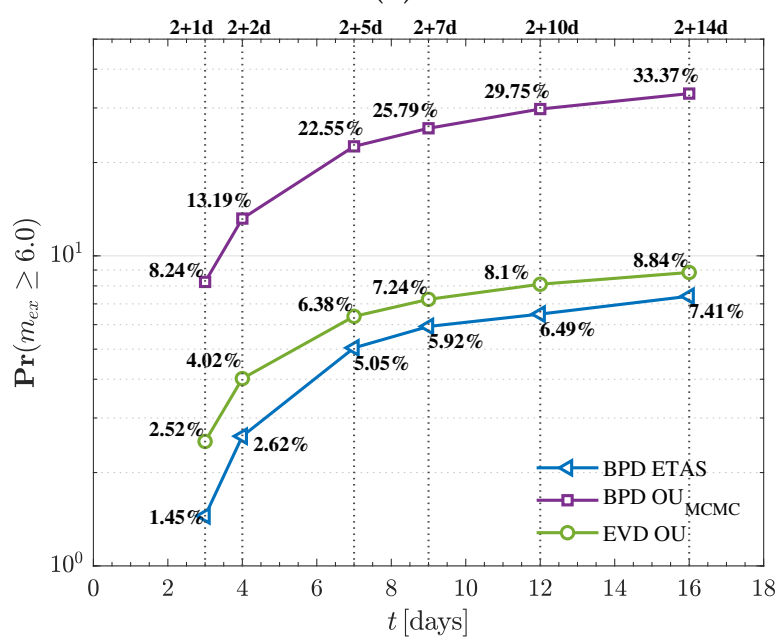

(c)

Figure A8. The comparison of the probabilities to have the largest expected aftershock during the target time interval of $\left[T_{s}, T_{e}\right]=[0.06,2]$ days for the three sequences: (a) 3 November 2002, $\mathrm{Mw}$ 7.9 Denali (b) 23 January 2018, Mw 7.9 Kodiak (c) 30 November 2018, Mw 7.1 Anchorage. The blue triangles are computed using the BPD, Equation (12), with an earthquake decay rate given by the ETAS model, Equation (6). The purple squares are computed using BPD, Equation (12), with an earthquake decay rate given by OU law, Equation (5). The green circles give probabilities computed using the EVD, Equation (11). The aftershock magnitudes are modelled using Equation (3). 


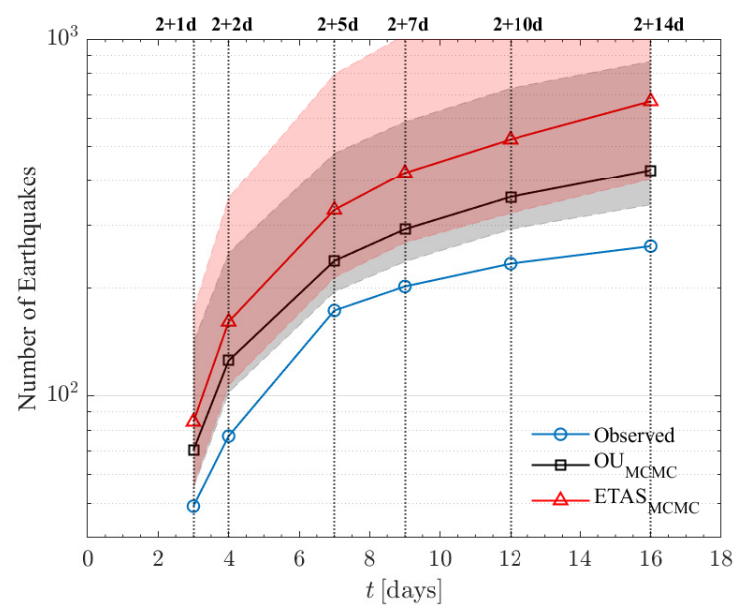

(a)

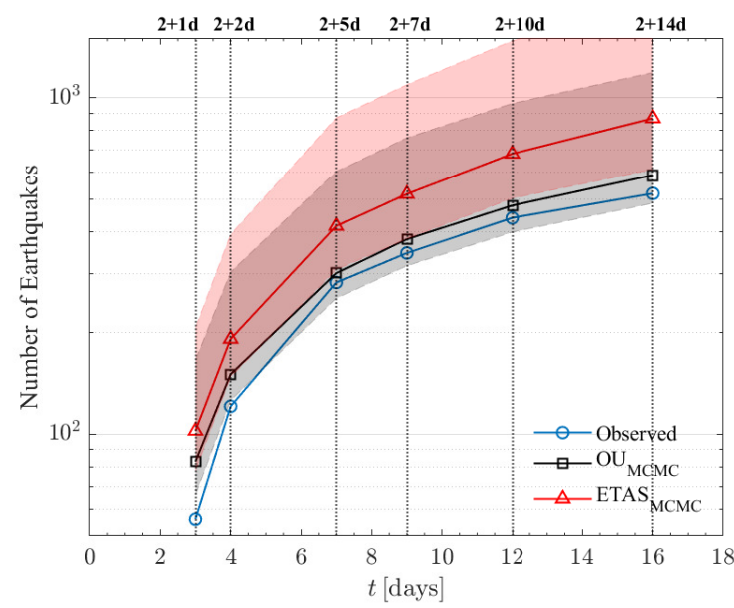

(b)

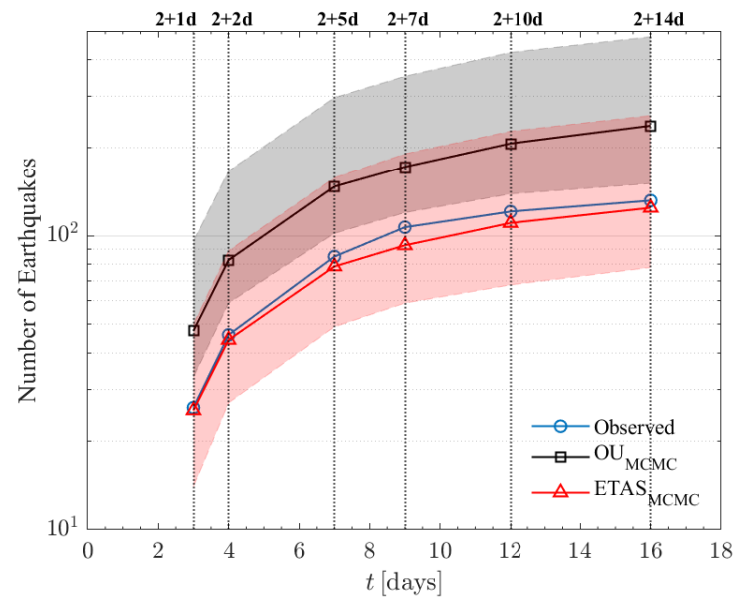

(c)

Figure A9. The number of forecasted and observed aftershocks in the forecasting time interval $\Delta T=[1,2,5,7,10,14]$ days for (a) The 3 November 2002, Mw 7.9 Denali for $m \geq 3.0$; (b) The 23 January 2018, Mw 7.9 Kodiak for $m \geq 3.2$; (c) The 30 November 2018, Mw 7.1 Anchorage for $m \geq 2.8$ by using the constant target time interval $\left[T_{s}, T_{e}\right]=[0.06,2]$ days. The red squares show the average number of forecasted earthquakes using the ETAS model, Equation (6), and the black triangles illustrate the average number of forecasted earthquakes using OU law, Equation (5). The shading bands represent $95 \%$ confidence intervals. The blue circles represents the observed number of earthquakes in the forecast time interval. 


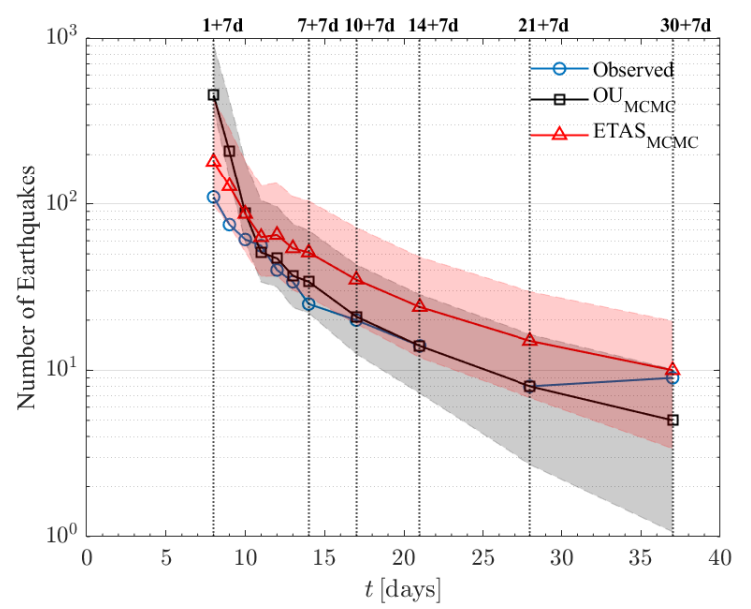

(a)

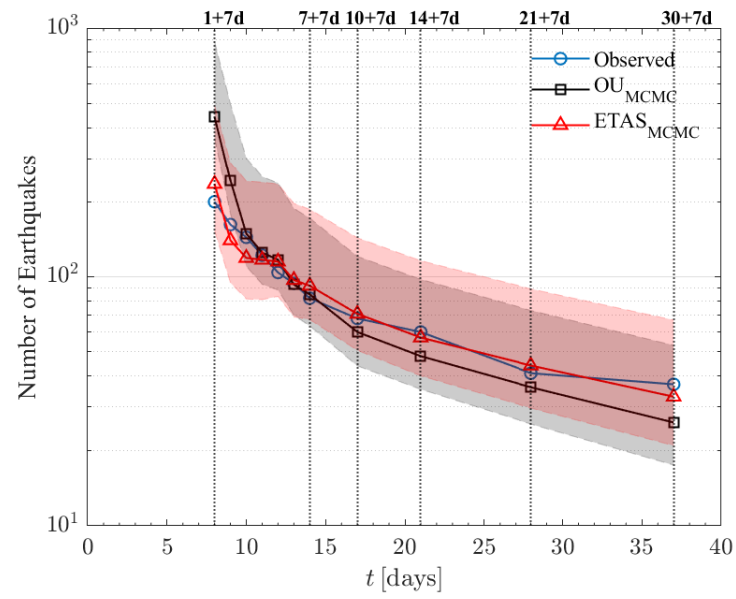

(b)

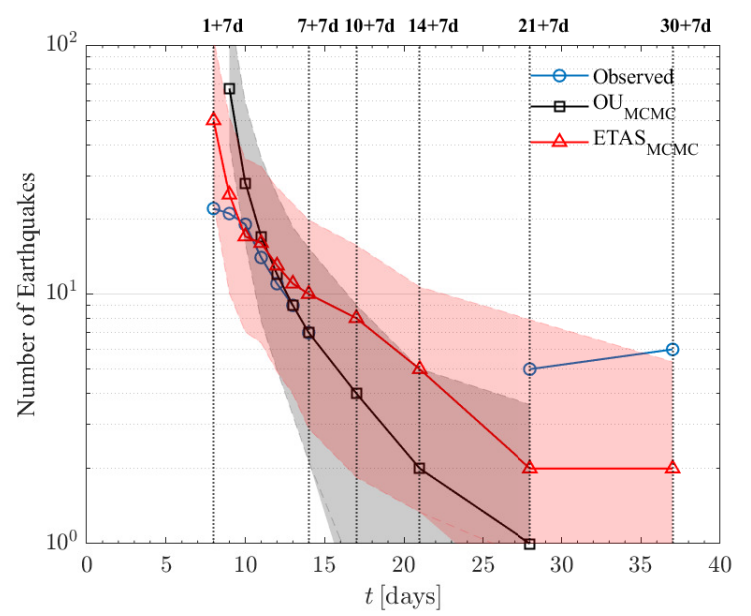

(c)

Figure A10. The number of forecasted and observed aftershocks in the forecasting time interval $\Delta T=7$ days for the three sequences: (a) the 3 November 2002, Mw 7.9 Denali sequence for $m \geq 3.5$; (b) the 23 January 2018, Mw 7.9 Kodiak sequence for $m \geq 3.5$; (c) the 30 November 2018, Mw 7.1 Anchorage sequence for $m \geq 3.5$. The red triangles show the average number of forecasted earthquakes using the ETAS model and the black squares illustrate the average number of forecasted earthquakes using OU law. The shading bands represent $95 \%$ confidence intervals. The blue circles represent the observed number of earthquakes in each forecasting time interval. 


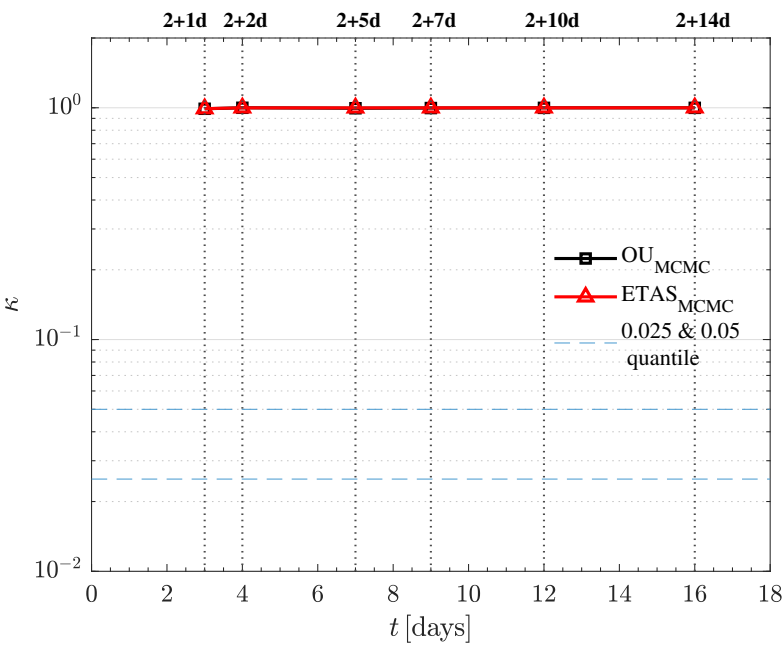

(a)

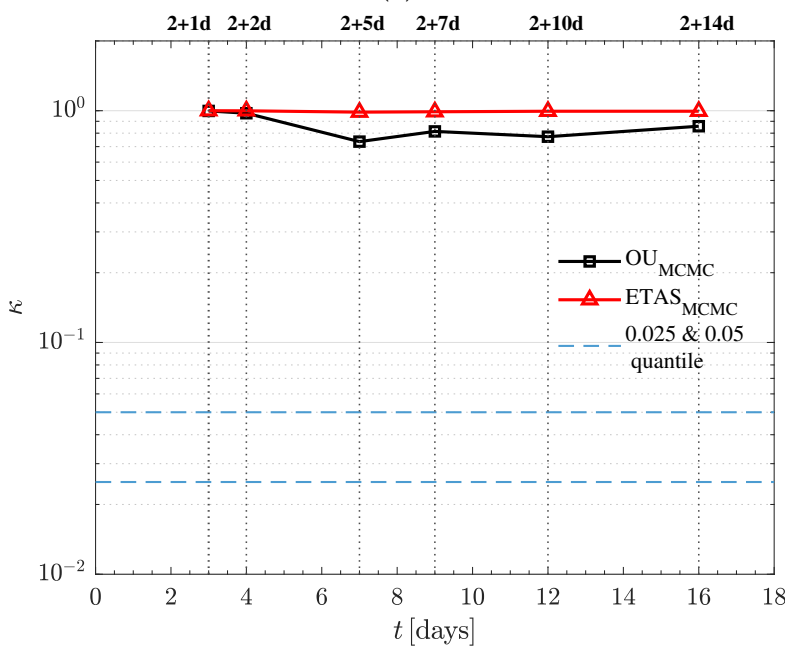

(b)

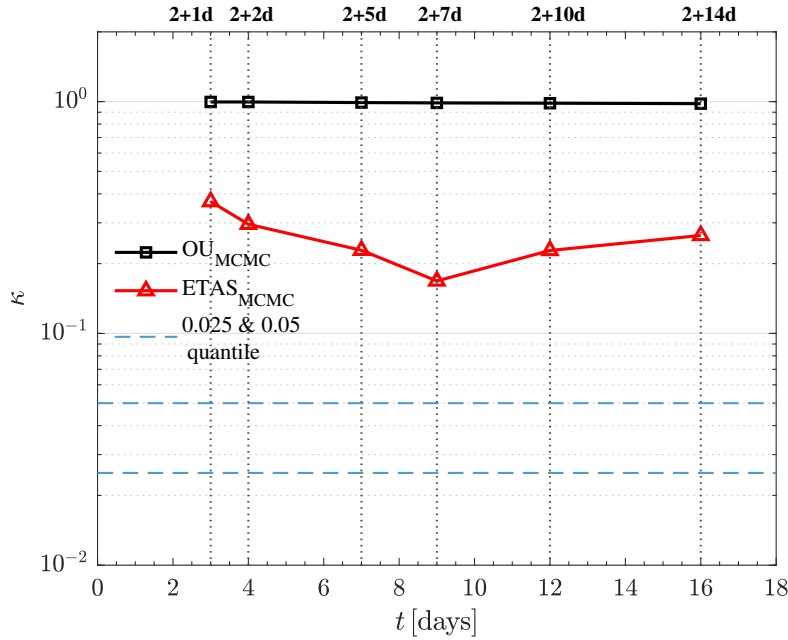

(c)

Figure A11. The obtained quantile scores from the M-test for the constant target time interval $\left[T_{s}, T_{e}\right]=[0.06,2]$ days for (a) The 3 November 2002, Mw 7.9 Denali for $m \geq 3.0$; (b) The 23 January 2018, Mw 7.9 Kodiak for $m \geq 3.2$; (c) The 30 November 2018, Mw 7.1 Anchorage for $m \geq 2.8$. The red triangles demonstrate the obtained quantile scores from the ETAS model, Equation (6), and the black squares illustrate the quantile scores of OU law, Equation (5). The blue dashed lines represent the 0.025 th and 0.05 th quantiles. 


\section{References}

1. Goda, K.; Pomonis, A.; Chian, S.; Offord, M.; Saito, K.; Sammonds, P.; Fraser, S.; Raby, A.; Macabuag, J. Ground motion characteristics and shaking damage of the 11th March 2011 Mw9.0 Great East Japan earthquake. Bull. Earthq. Eng. 2013, 11, 141-170. [CrossRef]

2. Daniell, J.; Schaefer, A.; Wenzel, F. Losses associated with secondary effects in earthquakes. Front. Built Environ. 2017, 3, 30. [CrossRef]

3. Shcherbakov, R.; Zhuang, J.; Zöller, G.; Ogata, Y. Forecasting the magnitude of the largest expected earthquake. Nat. Commun. 2019, 10, 4051. [CrossRef] [PubMed]

4. Shcherbakov, R. Statistics and Forecasting of Aftershocks During the 2019 Ridgecrest, California, Earthquake Sequence. J. Geophys. Res. Solid Earth 2021, 126, e2020JB020887. [CrossRef]

5. Båth, M. Lateral inhomogeneities of the upper mantle. Tectonophysics 1965, 2, 483-514. [CrossRef]

6. Vere-Jones, D. A note on the statistical interpretation of Båth's law. Bull. Seismol. Soc. Am. 1969, 59, 1535-1541. [CrossRef]

7. Vere-Jones, D. Stochastic Models for Earthquake Sequences. Geophys. J. Int. 1975, 42, 811-826. [CrossRef]

8. Reasenberg, P.A.; Jones, L.M. Earthquake Hazard after a Mainshock in California. Science 1989, 243, 1173-1176. [CrossRef]

9. Michael, A.J.; McBride, S.K.; Hardebeck, J.L.; Barall, M.; Martinez, E.; Page, M.T.; van der Elst, N.; Field, E.H.; Milner, K.R.; Wein, A.M. Statistical Seismology and Communication of the USGS Operational Aftershock Forecasts for the 30 November 2018 Mw 7.1 Anchorage, Alaska, Earthquake. Seismol. Res. Lett. 2019, 91, 153-173. [CrossRef]

10. Mignan, A.; Woessner, J. Estimating the magnitude of completeness for earthquake catalogs. Community Online Resour. Stat. Seism. Anal. 2012. [CrossRef]

11. Kagan, Y.Y. Short-term properties of earthquake catalogs and models of earthquake source. Bull. Seismol. Soc. Am. 2004, 94, 1207-1228. [CrossRef]

12. Peng, Z.G.; Vidale, J.E.; Houston, H. Anomalous early aftershock decay rate of the 2004 Mw 6.0 Parkfield, California, earthquake. Geophys. Res. Lett. 2006, 33, L17307. [CrossRef]

13. Omi, T.; Ogata, Y.; Hirata, Y.; Aihara, K. Estimating the ETAS model from an early aftershock sequence. Geophys. Res. Lett. 2014, 41, 850-857. [CrossRef]

14. Page, M.T.; van der Elst, N.; Hardebeck, J.; Felzer, K.; Michael, A.J. Three Ingredients for Improved Global Aftershock Forecasts: Tectonic Region, Time-Dependent Catalog Incompleteness, and Intersequence Variability. Bull. Seismol. Soc. Am. 2016, 106, 2290-2301. [CrossRef]

15. García, J.; Gómez Rico, M.; Molina Collado, A. A destination-branding model: An empirical analysis based on stakeholders. Tour. Manag. 2012, 33, 646-661. [CrossRef]

16. Gerstenberger, M.C.; Marzocchi, W.; Allen, T.; Pagani, M.; Adams, J.; Danciu, L.; Field, E.H.; Fujiwara, H.; Luco, N.; Ma, K.F.; et al. Probabilistic Seismic Hazard Analysis at Regional and National Scale: State of the Art and Future Challenges. Rev. Geophys. 2020, 58, e2019RG000653. [CrossRef]

17. Schorlemmer, D.; Gerstenberger, M.C.; Wiemer, S.; Jackson, D.D.; Rhoades, D.A. Earthquake likelihood model testing. Seismol. Res. Lett. 2007, 78, 17-29. [CrossRef]

18. Schorlemmer, D.; Werner, M.J.; Marzocchi, W.; Jordan, T.H.; Ogata, Y.; Jackson, D.D.; Mak, S.; Rhoades, D.A.; Gerstenberger, M.C.; Hirata, N.; et al. The Collaboratory for the Study of Earthquake Predictability: Achievements and Priorities. Seismol. Res. Lett. 2018, 89, 1305-1313. [CrossRef]

19. Zechar, J.D.; Gerstenberger, M.C.; Rhoades, D.A. Likelihood-Based Tests for Evaluating Space-Rate-Magnitude Earthquake Forecasts. Bull. Seismol. Soc. Am. 2010, 100, 1184-1195. [CrossRef]

20. Taroni, M.; Marzocchi, W.; Schorlemmer, D.; Werner, M.J.; Wiemer, S.; Zechar, J.D.; Heiniger, L.; Euchner, F. Prospective CSEP Evaluation of 1-Day, 3-Month, and 5-Yr Earthquake Forecasts for Italy. Seismol. Res. Lett. 2018, 89, 1251-1261. [CrossRef]

21. Nanjo, K.Z.; Tsuruoka, H.; Yokoi, S.; Ogata, Y.; Falcone, G.; Hirata, N.; Ishigaki, Y.; Jordan, T.H.; Kasahara, K.; Obara, K.; et al. Predictability study on the aftershock sequence following the 2011 Tohoku-Oki, Japan, earthquake: First results. Geophys. J. Int. 2012, 191, 653-658. [CrossRef]

22. Cattania, C.; Werner, M.J.; Marzocchi, W.; Hainzl, S.; Rhoades, D.; Gerstenberger, M.; Liukis, M.; Savran, W.; Christophersen, A.; Helmstetter, A.; et al. The Forecasting Skill of Physics-Based Seismicity Models during the 2010-2012 Canterbury, New Zealand, Earthquake Sequence. Seismol. Res. Lett. 2018, 89, 1238-1250. [CrossRef]

23. Rhoades, D.A.; Liukis, M.; Christophersen, A.; Gerstenberger, M.C. Retrospective tests of hybrid operational earthquake forecasting models for Canterbury. Geophys. J. Int. 2016, 204, 440-456. [CrossRef]

24. Rhoades, D.A.; Christophersen, A.; Gerstenberger, M.C.; Liukis, M.; Silva, F.; Marzocchi, W.; Werner, M.J.; Jordan, T.H. Highlights from the First Ten Years of the New Zealand Earthquake Forecast Testing Center. Seismol. Res. Lett. 2018, 89, 1229-1237. [CrossRef]

25. Lay, T.; Ye, L.; Bai, Y.; Cheung, K.F.; Kanamori, H. The 2018 MW 7.9 Gulf of Alaska earthquake: Multiple fault rupture in the Pacific plate. Geophys. Res. Lett. 2018, 45, 9542-9551. [CrossRef]

26. Ruppert, N.A.; Rollins, C.; Zhang, A.; Meng, L.; Holtkamp, S.G.; West, M.E.; Freymueller, J.T. Complex faulting and triggered rupture during the 2018 MW 7.9 offshore Kodiak, Alaska, earthquake. Geophys. Res. Lett. 2018, 45, 7533-7541. [CrossRef]

27. West, M.E.; Bender, A.; Gardine, M.; Gardine, L.; Gately, K.; Haeussler, P.; Hassan, W.; Meyer, F.; Richards, C.; Ruppert, N.; et al. The 30 November 2018 M w 7.1 Anchorage earthquake. Seismol. Res. Lett. 2020, 91, 66-84. [CrossRef] 
28. Gomberg, J. Slow-slip phenomena in Cascadia from 2007 and beyond: A review. Geol. Soc. Am. Bull. 2010, 122, 963-978. [CrossRef]

29. Bhattacharya, P.; Phan, M.; Shcherbakov, R. Statistical Analysis of the 2002 Mw 7.9 Denali Earthquake. Bull. Seismol. Soc. Am. 2011, 101, 2662-2674. [CrossRef]

30. Vere-Jones, D. Foundations of Statistical Seismology. Pure Appl. Geophys. 2010, 167, 645-653. [CrossRef]

31. Utsu, T. A statistical study on the occurrence of aftershocks. Geophys. Mag. 1961, 30, 521-605.

32. Ogata, Y. Statistics of Earthquake Activity: Models and Methods for Earthquake Predictability Studies. Annu. Rev. Earth Planet. Sci. 2017, 45, 497-527. [CrossRef]

33. USGS. Quaternary Fault and Fold Database. 2006. Available online: https://www.usgs.gov/natural-hazards/earthquakehazards/faults/ (accessed on 18 December 2021).

34. USGS. Mw 7.9 Central Alaska. 2015. Available online: https://earthquake.usgs.gov/earthquakes/eventpage/ak002e435qpj/ executive (accessed on 18 December 2021).

35. USGS. Mw 7.9 Kodiak Alaska. 2018. Available online: https://earthquake.usgs.gov/earthquakes/eventpage/us2000cmy3 / executive (accessed on 18 December 2021).

36. USGS. Mw 7.1 Anchorage Alaska. 2018. Available online: https://earthquake.usgs.gov/earthquakes/eventpage/ak20419010/ executive (accessed on 18 December 2021).

37. Krabbenhoeft, A.; von Huene, R.; Miller, J.J.; Lange, D.; Vera, F. Strike-slip 23 January 2018 MW 7.9 Gulf of Alaska rare intraplate earthquake: Complex rupture of a fracture zone system. Sci. Rep. 2018, 8, 13706. [CrossRef]

38. Guo, Y.; Miyakoshi, K.; Tsurugi, M. Simultaneous rupture on conjugate faults during the 2018 Anchorage, Alaska, intraslab earthquake (MW 7.1) inverted from strong-motion waveforms. Earth Planets Space 2020, 72, 176. [CrossRef]

39. Liu, C.; Lay, T.; Xie, Z.; Xiong, X. Intraslab deformation in the 30 November 2018 Anchorage, Alaska, MW 7.1 earthquake. Geophys. Res. Lett. 2019, 46, 2449-2457. [CrossRef]

40. Gutenberg, B.; Richter, C.F. Frequency of earthquakes in California. Bull. Seismol. Soc. Am. 1944, 4, 185-188. [CrossRef]

41. Bender, B. Maximum-likelihood estimation of $b$-values for magnitude grouped data. Bull. Seismol. Soc. Am. 1983, 73, 831-851. [CrossRef]

42. Tinti, S.; Mulargia, F. Confidence intervals of $b$-values for grouped magnitudes. Bull. Seismol. Soc. Am. 1987, 77, $2125-2134$.

43. Omori, F. On after-shocks of earthquakes. J. Coll. Sci. Imp. Univ. Tokyo 1894, 7, 113-200.

44. Ogata, Y. Estimation of the Parameters in the Modified Omori Formula for Aftershock Frequencies by the Maximum-Likelihood Procedure. J. Phys. Earth 1983, 31, 115-124. [CrossRef]

45. Ogata, Y. Seismicity analysis through point-process modeling: A review. Pure Appl. Geophys. 1999, 155, 471-507. [CrossRef]

46. Ogata, Y. Statistical-Models For Earthquake Occurrences And Residual Analysis For Point-Processes. J. Am. Stat. Assoc. 1988, 83, 9-27. [CrossRef]

47. Daley, D.J.; Vere-Jones, D. An Introduction to the Theory of Point Processes, 2nd ed.; Springer: New York, NY, USA, 2003 ; Volume 1.

48. Shcherbakov, R.; Zhuang, J.; Ogata, Y. Constraining the magnitude of the largest event in a foreshock-mainshock-aftershock sequence. [CrossRef]

49. Rhoades, D.A.; Schorlemmer, D.; Gerstenberger, M.C.; Christophersen, A.; Zechar, J.D.; Imoto, M. Efficient testing of earthquake forecasting models. Acta Geophys. 2011, 59, 728-747. [CrossRef]

50. Wiemer, S.; Wyss, M. Minimum magnitude of completeness in earthquake catalogs: Examples from Alaska, the western United States, and Japan. Bull. Seismol. Soc. Am. 2000, 90, 859-869. [CrossRef]

51. Zhuang, J.; Ogata, Y.; Wang, T. Data completeness of the Kumamoto earthquake sequence in the JMA catalog and its influence on the estimation of the ETAS parameters. Earth Planets Space 2017, 69, 1-12. [CrossRef]

52. Gulia, L.; Rinaldi, A.P.; Tormann, T.; Vannucci, G.; Enescu, B.; Wiemer, S. The effect of a mainshock on the size distribution of the aftershocks. Geophys. Res. Lett. 2018, 45, 13-277. [CrossRef]

53. Spassiani, I.; Marzocchi, W. An Energy-Dependent Earthquake Moment-Frequency Distribution. Bull. Seismol. Soc. Am. 2021, 111, 762-774. [CrossRef] 